\title{
Advancement in corrosion resistance of AA 2024-T3 through sol-gel coatings including nanocontainers
}

\author{
Ioannis A. Kartsonakis, Elias P. Koumoulos, and Costas A. Charitidis* \\ RNanolab, School of Chemical Engineering, National Technical University of Athens, 15780, Greece
}

Received 24 November 2016 / Accepted 3 January 2017

\begin{abstract}
The current study investigates the effect of nanocontainers incorporation into sol-gel coatings for the protection improvement of aluminium alloys 2024-T3 against corrosion. The nanocontainers were synthesized via a combination of radical polymerization process and sol-gel technique. They consist of cerium and molybdenum oxides and loaded with the anodic corrosion inhibitor 2-mercaptobenzothiazole (MBT). The preparation of the coating matrix was accomplished using (3-glycidoxypropyl)trimethoxysilane as precursor. These organic modified silicate based sol-gel films were evaluated for their corrosion behaviour as well as nanomechanical properties using electrochemical and nanoindentation techniques, respectively. The results reveal that the presence of loaded nanocontainers improved the corrosion protection of the coatings; outcome that can be attributed to either the increase coherence of the coating or the simultaneously inhibition action of cerium and molybdate ions together with the corrosion inhibitor MBT. Moreover, the addition of nanocontainers empty or loaded with inhibitor amount strengthens (increase of wear resistance) the coating and decreases the coefficient of friction.
\end{abstract}

Key words: Aluminium, Nanocontainers, EIS, Pitting Corrosion, Nanoindentation

\section{Introduction}

Aluminium alloy (AA) 2024-T3 is widely used in aerospace industry due to its low cost, lightweight and high mechanical strength. Furthermore, it demonstrates as good fatigue resistance as well high strength to weight ratio. On the contrary, this alloy is highly susceptible to corrosion because of the presence of intermetallic particles at the surface resulting in a need for the development of several methods in order to enhance its resistance against corrosion [1, 2]. During the previous years, chromate based coatings used to be the most effective method, exhibiting excellent anticorrosion properties that are ascribed to the strong oxidation properties of $\mathrm{Cr}(\mathrm{VI})$. Unfortunately, $\mathrm{Cr}(\mathrm{VI})$ and $\mathrm{Cr}(\mathrm{III})$ ions are very toxic and provoke serious human diseases [3]. An alternative, environmentally friendly, protection to metal alloys is based on sol-gel coatings [1]. These coatings protect the metal surface by creating a physical and chemical barrier between the metal and its environment [4]. The accomplishment of improved corrosion protective properties of the sol-gel coatings requires that, not only the synthesized sol-gel coatings have to be homogeneous and crack free but also they should present low porosity [5].

*e-mail: charitidis@chemeng.ntua.gr
Comparing with chromate based coatings, it may be remarked that sol-gel coatings do not demonstrate self-healing properties when the coating is partially damaged. Nevertheless, this disadvantage can be overcome by the addition of inorganic or organic corrosion inhibitors into the coatings that can provide self-healing properties to sol-gel coatings [6-8]. Furthermore, the corrosion inhibitors can be encapsulated into containers before their incorporation into the coatings in order to control the release of inhibitor without loss of the coatings coherence [9-13].

The mechanical integrity of the protective coatings is also an important factor apart from their anticorrosive properties. Nanoindentation and nanoscratch tests are widely performed for the mechanical properties evaluation of thin films [14]. The nanoindentation test can provide information about the mechanical behaviour of the material when it is being deformed at the sub-micron scale. The method developed by Oliver and Pharr [15] allows determining the elastic modulus as well as the hardness from the nanoindentation load-displacement data.

The present work is focused on the combination of nanocontainers with sol-gel coatings for the protection of AA 2024-T3. The study investigates not only the overall corrosion protection of the system coating-containers but also the contribution of each parameter (type of nanocontainers, 
corrosion inhibitor). The nanocontainers consist of cerium molybdate (CeMo) because cerium cation and molybdate anion are corrosion inhibitors in themselves [16-19]. Furthermore, the nanocontainers had been loaded with corrosion inhibitor 2-mercaptobenzothiazole (MBT) prior to their incorporation to the coatings. MBT was selected due to its corrosion inhibitor properties as well as its better corrosion protection properties when compared to other inhibitors [7]. Finally, studies on the nano-mechanical properties of the aforementioned coatings were also conducted.

\section{Materials and methods}

The chemical composition limits for the used AA 2024-T3 panels is listed in Table 1. All chemicals were of analytical reagent grade. Cerium (III) acetylacetonate $\left(\mathrm{Ce}(\mathrm{acac})_{3}\right.$, Sigma-Aldrich, St. Louis, USA), MBT (Sigma-Aldrich, St. Louis, USA), sodium molybdate $\left(\mathrm{Na}_{2} \mathrm{MoO}_{4}\right.$, Sigma-Aldrich, St. Louis, USA), acetonitrile (Sigma-Aldrich, St. Louis, USA), potassium persulfate (KPS, Sigma-Aldrich, St. Louis, USA), (3-glycidoxypropyl)trimethoxysilane (GPTMS, Sigma-Aldrich, St. Louis, USA) and absolute ethanol (Sigma-Aldrich, St. Louis, USA), were used without further purification. Methacrylic acid (MAA, Sigma-Aldrich, St. Louis, USA) was double distilled under reduced pressure prior to use.

The CeMo nanocontainers were synthesized according to the following process. Firstly, cores of CeMo containers were produced using anionic charged polymethacrylic nanospheres as templates [20]. The production of templates was accomplished via radical polymerization using acetonitrile as a solvent, MAA as a monomer and KPS as an initiator. The produced polymethacrylic acid (PMAA) nanospheres were coated with cerium molybdenum oxide using $\mathrm{Ce}(\mathrm{acac})_{3}$ and $\mathrm{Na}_{2} \mathrm{MoO}_{4}$ as precursors via the sol-gel process. The CeMo containers were acquired after successive dispersion in ethanol in order to remove the PMAA template, centrifugation, drying in air and calcination at $550{ }^{\circ} \mathrm{C}$ for $3 \mathrm{~h}$. The nanocontainers loading was performed via the insertion of a saturated solution of MBT in acetone into the CeMo nanocontainers that had been previously degased under vacuum conditions [21].

The coatings were deposited onto the metal panels via a dip-coating process. Optimum protection of AA 2024-T3 was achieved by a coating formed with a GPTMS/acetic acid/water molar ratio of 3/1/10 solution, a constant withdrawing speed of $5.33 \mathrm{~mm} / \mathrm{s}$ and curing at $100{ }^{\circ} \mathrm{C}$ for $36 \mathrm{~h}$. Each panel was dipped three times and each time it remained in the solution for $1 \mathrm{~min}$. The specimens were withdrawn in a direction parallel to their lengths. Table 2 tabulates the four different types of coatings that were prepared. All the panels were chemically cleaned prior to application of the coatings. The treatment of the panels comprises consecutive submersion in 2 wt. $\% \mathrm{NaOH}$ solution at $40{ }^{\circ} \mathrm{C}$ for $3 \mathrm{~min}$ and in $4.33 \mathrm{M} \mathrm{HNO}_{3}$ for $30 \mathrm{~s}$, while being washed in distilled water between the cleaning stages of the process and afterwards. Finally, they were left to dry in air and then transferred to a desiccator.

Both the average nanocontainer size, the morphology of the coatings as well as their elemental analysis were estimated
Table 1. Chemical composition limits of AA 2024-T3 (wt.\%).

\begin{tabular}{ccccccccr}
\hline $\mathrm{Si}$ & $\mathrm{Fe}$ & $\mathrm{Cu}$ & $\mathrm{Mn}$ & $\mathrm{Mg}$ & $\mathrm{Cr}$ & $\mathrm{Zn}$ & $\mathrm{Ti}$ & $\mathrm{Al}$ \\
\hline 0.5 & 0.5 & $3.8-4.9$ & $0.3-0.9$ & $1.2-1.8$ & 0.1 & 0.25 & 0.15 & bal. \\
\hline
\end{tabular}

Table 2. The produced types of coatings.

\begin{tabular}{ll}
\hline \multicolumn{1}{c}{ Specimen } & \multicolumn{1}{c}{ Sample } \\
\hline Coating without nanocontainers & AA-coat \\
Coating including 4 wt.\% MBT & AA-coat-MBT \\
$\begin{array}{l}\text { Coating including 4 wt.\% empty } \\
\text { nanocontainers }\end{array}$ & AA-coat-CeMo \\
$\begin{array}{l}\text { Coating including } 4 \text { wt.\% nanocontainers } \\
\text { loaded with MBT }\end{array}$ & AA-coat-CeMo-MBT \\
\hline
\end{tabular}

by scanning electron microscopy (SEM) and energy dispersive $\mathrm{X}$-ray analysis spectroscopy (EDS) using a PHILIPS Quanta Inspect (FEI Company) microscope with W (tungsten) filament $25 \mathrm{KV}$ equipped with EDAX GENESIS (AMETEX PROCESS \& ANALYTICAL INSTRUMENTS) and Transmission Electron Microscope (TEM) using a JEM2000 FX (200 KV, resolution $0.28 \mathrm{~nm}$ ). The chemical analysis of the coatings was conducted via Fourier Transform Infrared Spectroscopy (FT-IR) using a FT-IR attenuated total reflectance Agilent Cary 630 instrument in the range of $400-4000 \mathrm{~cm}^{-1}$. The loading of the inhibitor into the nanocontainers was estimated by thermogravimetric analysis (TGA) using a TA Q50 instrument at the heating rate of $10{ }^{\circ} \mathrm{C} \mathrm{min}{ }^{-1}$ in air.

The corrosion behaviour of the coatings was estimated via electrochemical impedance spectroscopy (EIS) using a Princeton Applied Research EG \& G 263A potentiostat instrument connected with a SI 1260 Impedance/Phase-Gain analyser. The experiments were conducted at the open circuit potential, in a Faraday cage, at room temperature, using a three-electrode electrochemical cell, consisting of a saturated silver chloride electrode $(\mathrm{Ag} / \mathrm{AgCl}, \mathrm{KCl}(\mathrm{sat}))$ as reference, a working electrode $\left(\approx 1.0 \mathrm{~cm}^{2}\right.$ of exposed area) and a platinum foil as counter electrode. The root mean square (rms) voltage was $10 \mathrm{mV}$ and the measuring frequency ranged from $50 \mathrm{kHz}$ down to $5 \mathrm{mHz}$. The Z-view Software applying the adequate equivalent electric circuits was used for the EIS spectra treatment. The corrosive solution that was used was $50 \mathrm{mM} \mathrm{NaCl}$ prepared with distilled water.

Nanoindentation testing was performed with a Hysitron TriboLab Nanomechanical Test Instrument, which allows the application of loads from 1 to $30,000 \mu \mathrm{N}$ and records the displacement as a function of applied loads with a high load resolution $(1 \mathrm{nN})$ and a high displacement resolution. The nanomechanical test instrument employed in this study is equipped with a Scanning Probe Microscope (SPM), in which a sharp probe tip moves in a raster scan pattern across a sample surface using a three-axis piezo positioner. In all depth-sensing tests a total of 10 indents are averaged to determine the mean hardness $(H)$ and elastic modulus $(E)$ values for statistical purposes, in a clean area environment with $45 \%$ humidity and $23{ }^{\circ} \mathrm{C}$ ambient temperature. In order to operate under closed loop load control, feedback control option was 
(a)

(b)
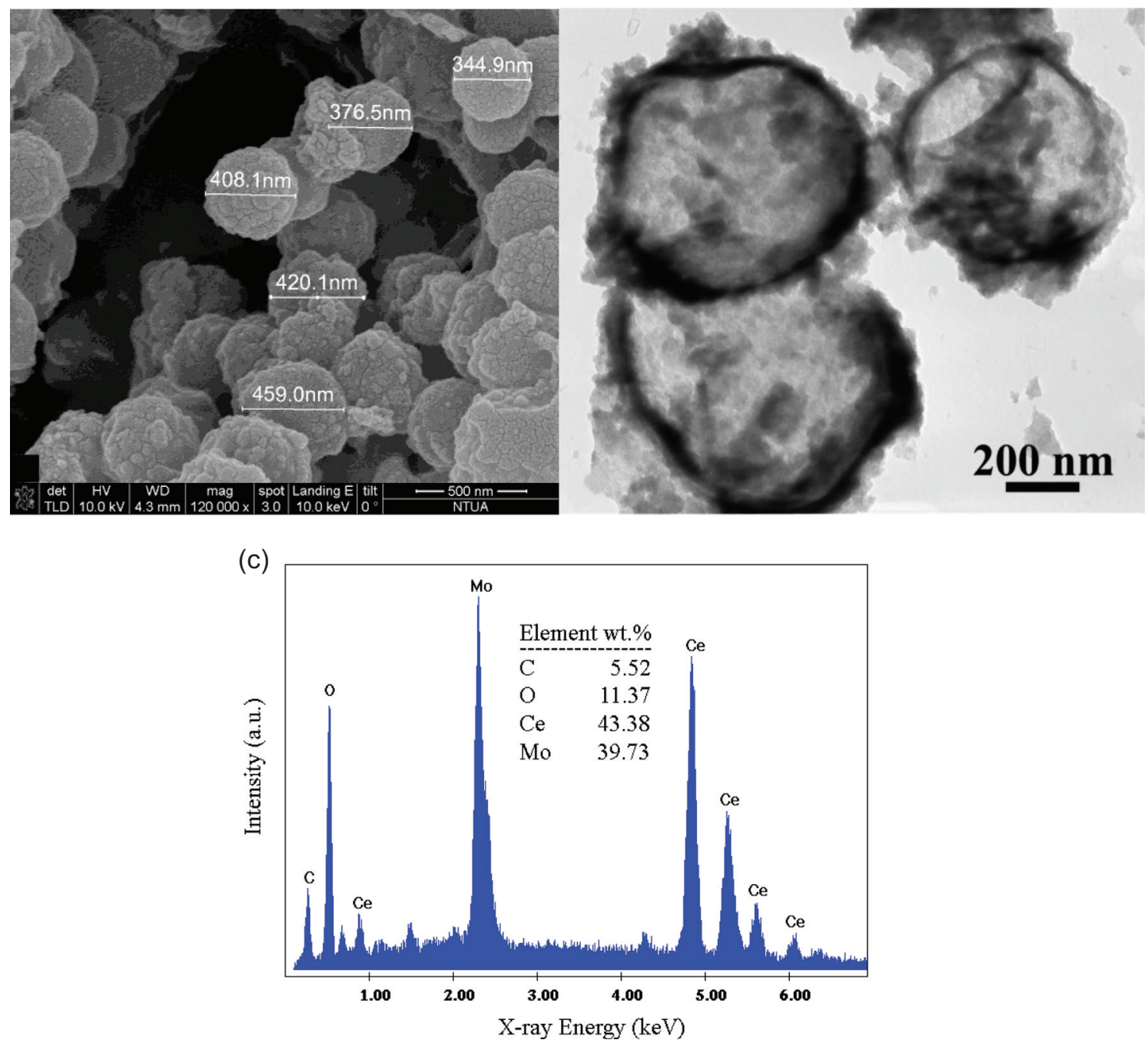

Figure 1. (a) SEM image, (b) TEM image and (c) EDS analysis of cerium molybdate nanocontainers.

used. All nanoindentation measurements have been performed with the standard three-sided pyramidal Berkovich probe, with an average radius of curvature of about $100 \mathrm{~nm}$ [14], with $40 \mathrm{~s}$ loading and unloading segment time separately and $3 \mathrm{~s}$ of holding time, to avoid residual viscoelasticity. Prior to indentation, the area function of the indenter tip was measured in a fused silica, a standard material for this purpose [22]. The scratch tests performed in this work included three main segments. Firstly, a pre-scan under a very small load $(1 \mu \mathrm{N})$ was carried out; then, the indenter scraped the sample under a certain force and a scratch would be generated. The normal applied loads were $300 \mu \mathrm{N}$, while the length of the scratches was $8 \mu \mathrm{m}$.

\section{Results and discussion}

\subsection{Morphology study}

The morphology images of the synthesized containers are demonstrated in Figure 1. It is evident from the SEM and
TEM images that the fabricated containers are hollow spheres but not uniform in size; their diameter ranges from $340 \mathrm{~nm}$ to $460 \mathrm{~nm}$ (Figures 1a, 1b). The EDS analysis reveals that the containers consist of cerium, molybdenum and oxygen (Figure 1c).

Figure 2 depicts the TGA diagrams of pure MBT and CeMo containers loaded with MBT. It can be seen that there is a retardation in the corrosion inhibitor burn off in the system MBT-CeMo nanocontainers $\left(760{ }^{\circ} \mathrm{C}\right.$, Figure $\left.2 b\right)$ compared to the burn off of pure MBT $\left(310^{\circ} \mathrm{C}\right.$, Figure $\left.2 \mathrm{a}\right)$. This indication can be assigned to the encapsulation of MBT into the CeMo containers [23]. The thermogravimetric analysis of the spectrum in Figure $2 \mathrm{~b}$ shows three different sharp weight losses from the low temperature to high temperature attributed to the burn off of the inhibitor that is on the shell (lower temperature range), into the pores of the shell (middle temperature range) and inside the shell of the nanocontainer (higher temperature range), respectively. Taking into account the overall weight loss of the spectrum in Figure $2 b$ between $150{ }^{\circ} \mathrm{C}$ and $760{ }^{\circ} \mathrm{C}(2.27 \mathrm{mg})$, it may be remarked that the nanocontainers were $24.3 \mathrm{wt} \%$ loaded with MBT. 

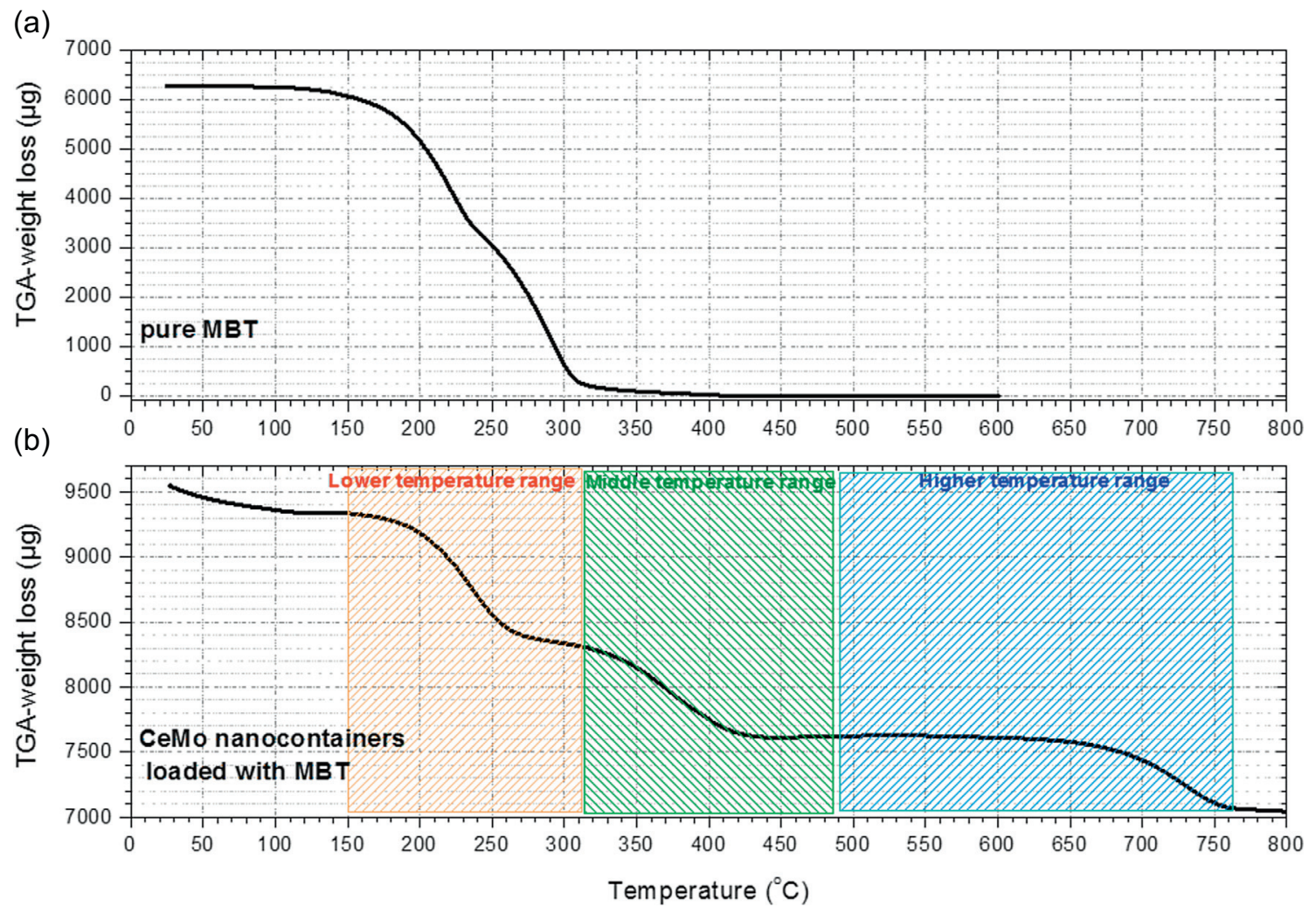

Figure 2. TGA curves of (a) pure MBT and (b) cerium molybdate nanocontainers loaded with MBT.

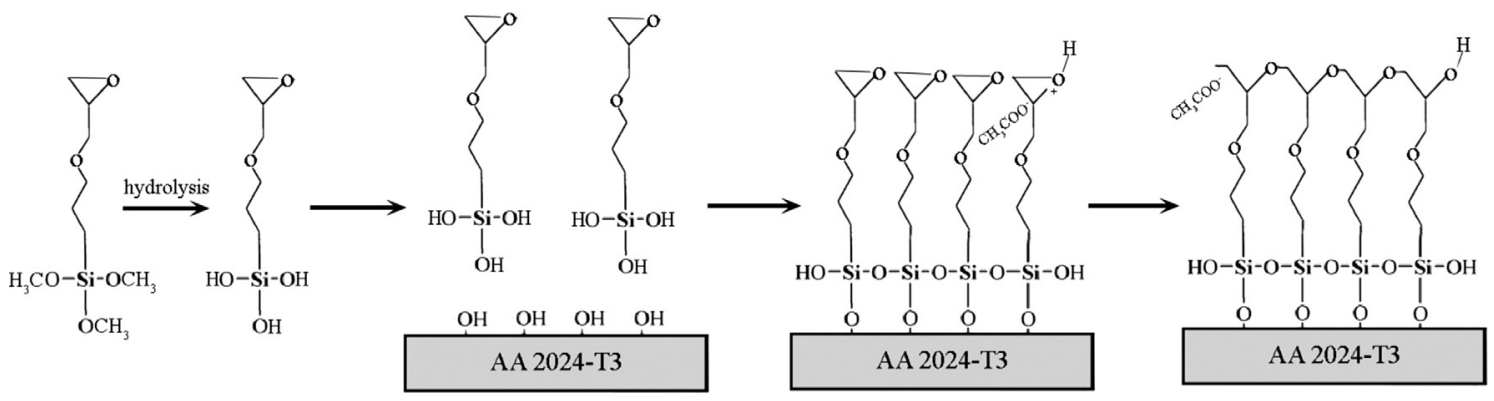

Figure 3. Schematic representation of the coating formation on AA 2024-T3.

However, not all of the MBT is encapsulated in the nanocontainers. A part of MBT is adsorbed into the shell and into the pores of the shell of the nanocontainers shown by the sharp increase in weight losses.

The synthesis of the applied coating that consists of GPTMS/acetic acid/water with a molar ratio of $3 / 1 / 10$ is based to the following reactions. At first, the surface of AA 2024-T3 panels is activated with hydroxyl groups via the cleaning process. Moreover, the trimethoxysilyl- groups of GPTMS molecules are hydrolysed resulting in hydroxylsilyl- group. The resulting hydroxylsilyl- groups of GPTMS are covalently bonded with either the hydroxyl groups of the metal surface or the hydroxylsilyl- groups of other GPTMS molecules. The presence of acetic acid leads to the polymerization between the epoxy groups of the GPTMS molecules through an $\mathrm{S}_{\mathrm{N}} 2$ mechanism. The epoxy polymerization is initiated by the nucleophile attack of the acetic acid on the epoxy carbon and the nucleophile oxygen of the epoxide ring attacks another epoxy carbon propagating the chain. The whole process results in the formation of a coating onto the metal substrate that is schematically represented in Figure 3.

The surface SEM images as well as the corresponding tabulated values of the coatings EDS analyses are shown in Figure 4 and Table 3, respectively. All the coatings are crack free with visible white agglomerates, some of which were identified by EDS as Si-rich. Moreover, the surface of the coatings including nanocontainers loaded or empty (Figures $4 \mathrm{a}$ and $4 \mathrm{~b}$, respectively) exhibit a large number of white agglomerations that are assigned to the presence of CeMo 
(a)

(b)

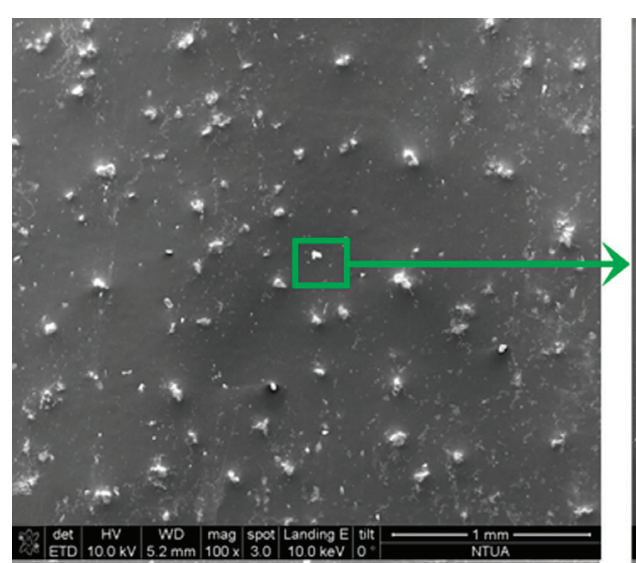

(c)
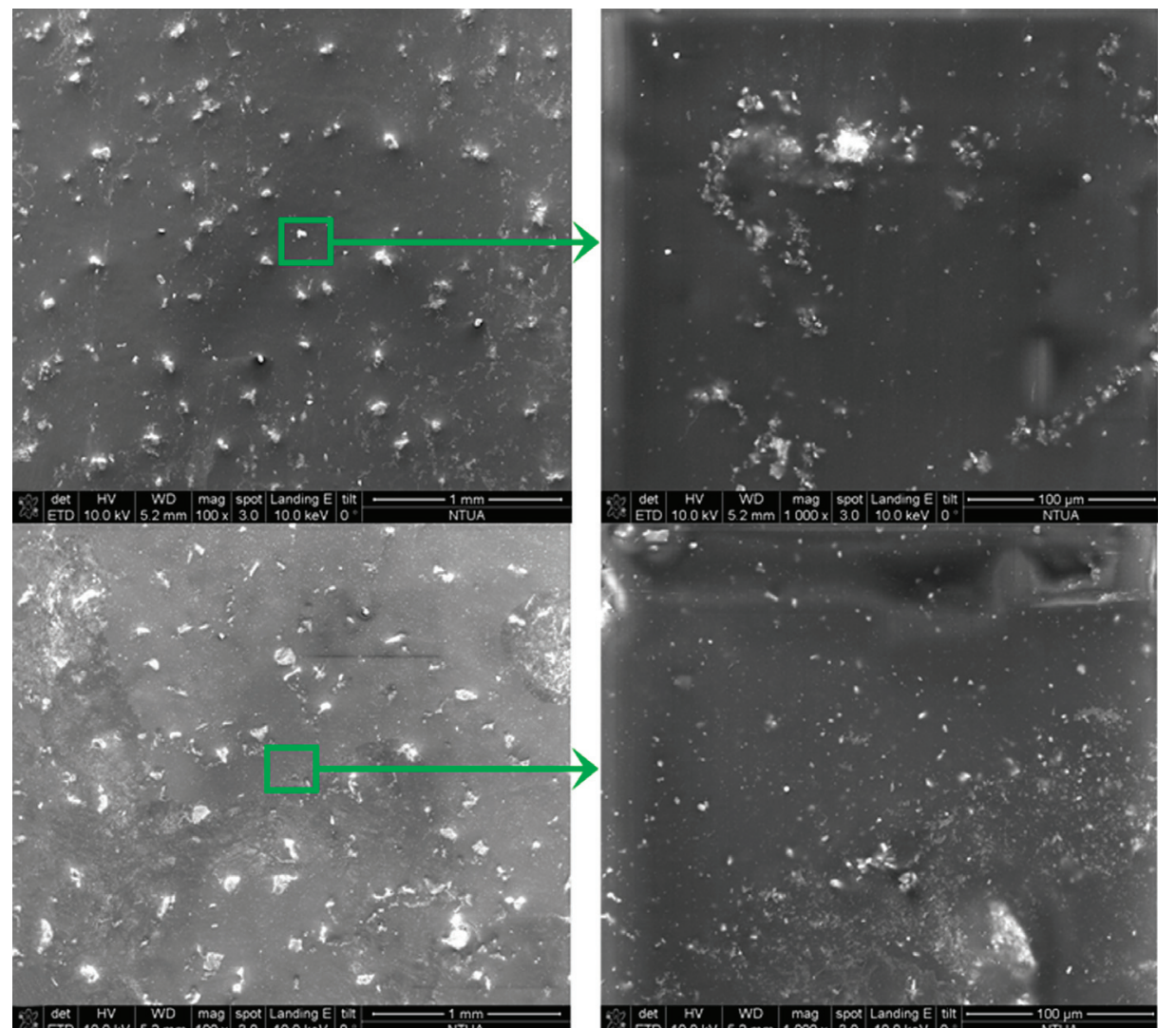

)

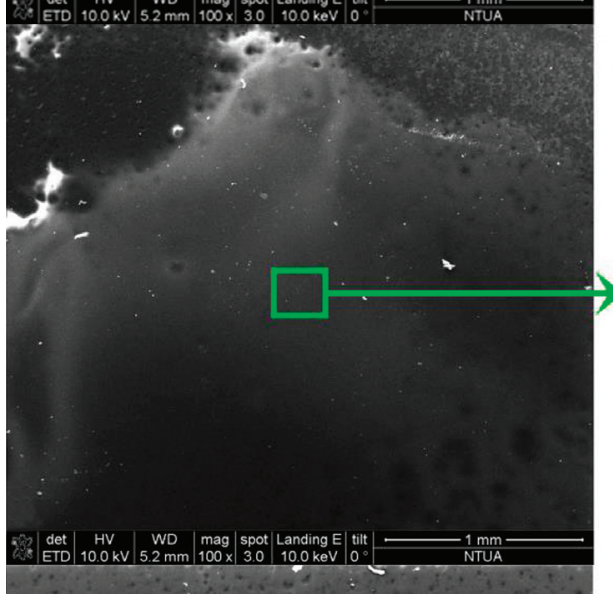

(d)

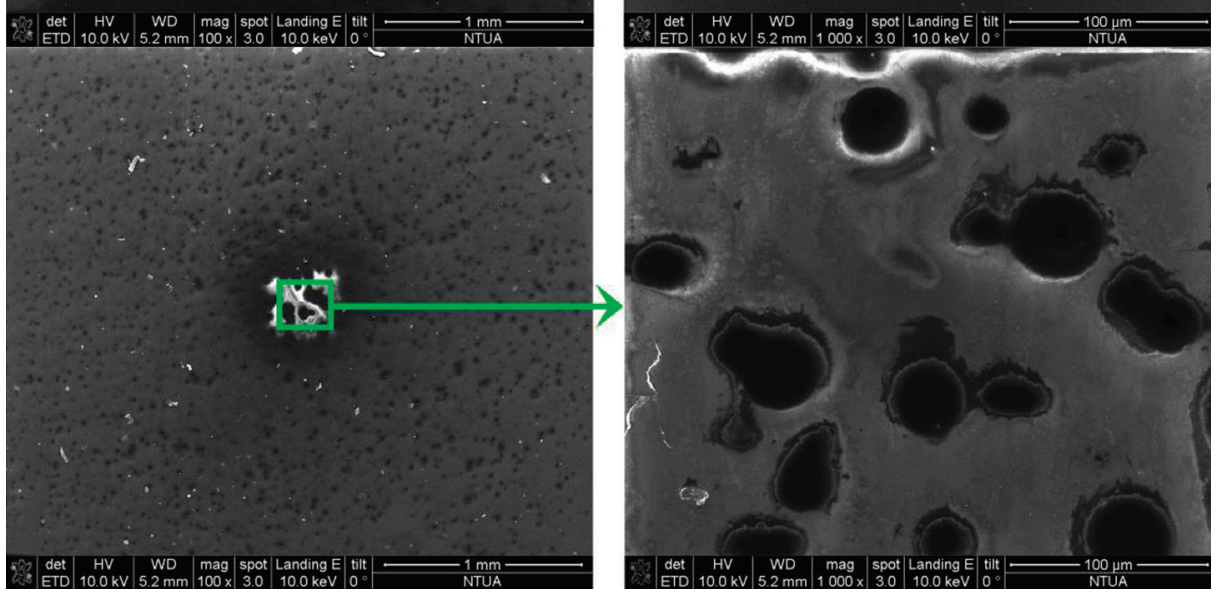

Figure 4. Surface morphology of coatings: (a) AA-coat-CeMo-MBT, (b) AA-coat-CeMo, (c) AA-coat-MBT and (d) AA-coat. 
Table 3. Tabulated values of wt. $\%$ element concentration of the produced coatings prior exposure to $50 \mathrm{mM} \mathrm{NaCl}$.

\begin{tabular}{lcccccc}
\hline & $\mathrm{C}$ & $\mathrm{O}$ & $\mathrm{Si}$ & $\mathrm{Mo}$ & $\mathrm{S}$ & $\mathrm{Ce}$ \\
\hline AA-coat & 52.49 & 28.42 & 19.09 & - & - & - \\
AA-coat-MBT & 51.73 & 28.58 & 18.84 & - & 0.85 & - \\
AA-coat-CeMo & 50.60 & 25.45 & 18.56 & 3.67 & - & 1.72 \\
AA-coat-CeMo-MBT & 51.57 & 21.28 & 19.04 & 4.74 & 0.44 & 2.93 \\
\hline
\end{tabular}

(a)

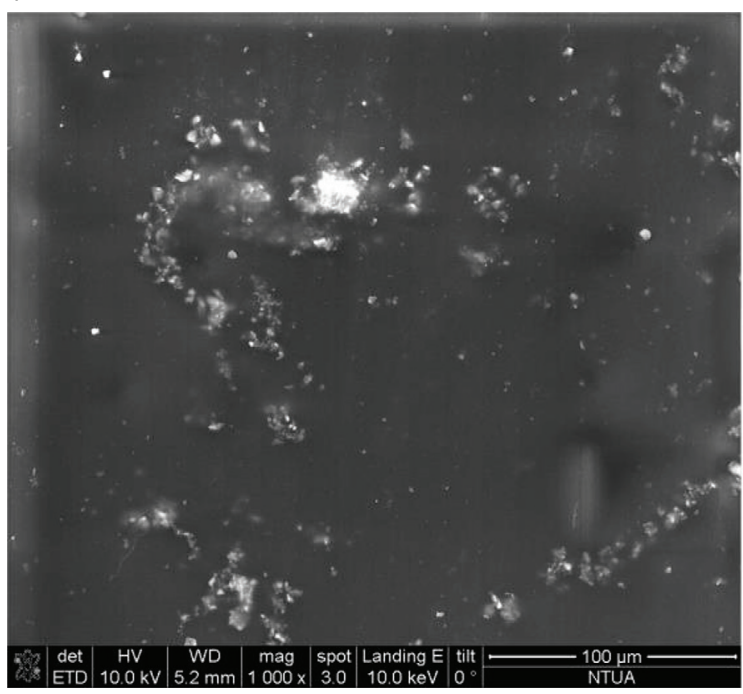

(b)

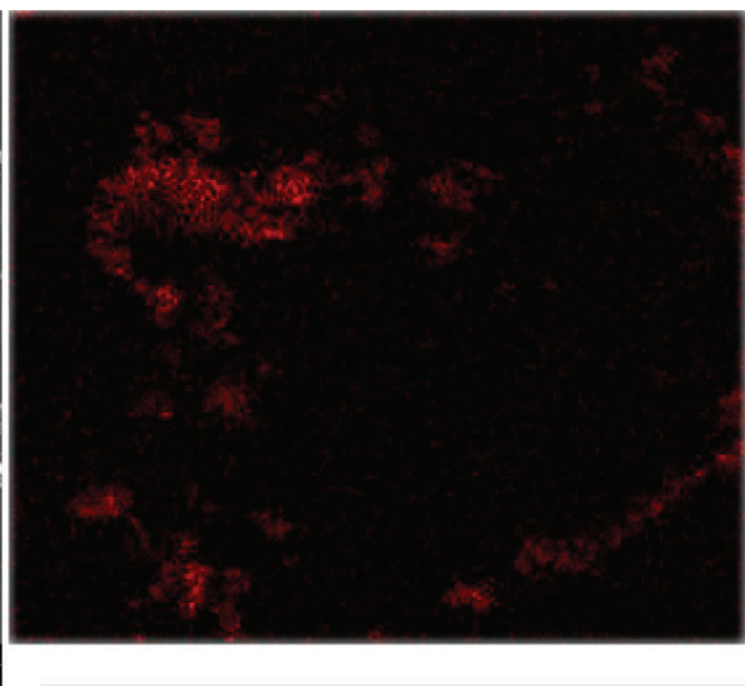

Figure 5. Mapping micrograph (a) and corresponding SEM image (b) of coating AA-coat-CeMo-MBT.

nanocontainers, after evaluation via EDS analysis. Finally, the image of the coating without nanocontainers demonstrates lots of pin-holes (Figure 4d).

Figure 5 illustrates the cerium elemental mapping analysis and the corresponding SEM micrograph of the surface for the coating including CeMo loaded nanocontainers. It can be seen that some of the nanocontainers have been agglomerated. On the other hand, no part of the surface is free of nanocontainers. This result indicates that the nanocontainers have been distributed into all of the coating. Another important factor is the dispersion of the nanocontainers through the thickness of the coating. The nanocontainers should not be agglomerated on the top or on the interface between the coating and the substrate.

Taking into account Figure 6 that presents the cerium elemental mapping analysis through the thickness of the coating and the corresponding SEM micrograph, it may be remarked that the CeMo nanocontainers have been well dispersed through the coating thickness without aggregations.

The thickness of each coating is depicted in Figure 7. AA-coat-CeMo-MBT coating has a thickness from $35 \mathrm{~nm}$ to $40 \mathrm{~nm}$ (Figure 7a) while the coating including empty nanocontainers has a thickness from $31 \mathrm{~nm}$ to $35 \mathrm{~nm}$ (Figure 7b). The coating including only the inhibitor (AA-coat-MBT) has an estimated thickness range of $36 \mathrm{~nm}-38 \mathrm{~nm}$ (Figure 7c). Finally, the coating AA-coat has a thickness from $28 \mathrm{~nm}$ to $33 \mathrm{~nm}$ (Figure 7d). Regarding the aforementioned results, it may be remarked that the coating including the nanocontainers loaded with corrosion inhibitor has the maximum thickness whereas the coating without additives has the lowest thickness of the four coatings.

\subsection{FT-IR analysis}

Analysis of the structure and of the chemical composition of the coatings was evaluated via FT-IR (Figure 8). The identification of the coating peaks is depicted in Table 4 [24, 25]. Considering Table 4, all the characteristic peaks of the vibrations of groups that are ascribed to the inorganic and organic network such as $\mathrm{Si}-\mathrm{O}-\mathrm{Si}$, epoxy ring, $\mathrm{C}-\mathrm{H}, \mathrm{H}-\mathrm{C}-\mathrm{H}$, $\mathrm{C}=\mathrm{O}, \mathrm{C}-\mathrm{O}-\mathrm{C}, \mathrm{C}-\mathrm{C}$ and Al-O-Si can be clearly seen. Apart from these peaks, the coatings including nanocontainers reveal additional absorption peak at $895 \mathrm{~cm}^{-1}$ which is ascribed to molybdate ion. The broad peaks observed in this compound at 724 and $828 \mathrm{~cm}^{-1}$ are attributed to the overlapping of the bands of $\mathrm{Ce}(\mathrm{OH})^{+2}$ and molybdate ion in the regions of $450-800 \mathrm{~cm}^{-1}[20]$.

\subsection{Corrosion study}

The coatings produced with and without additives were studied for their protective properties against corrosion of the aluminium substrate. All the electrochemical characterizations include the exposure of the coated substrates to $400 \mathrm{~mL}$ of $50 \mathrm{mM} \mathrm{NaCl}$ solution prepared with distilled water with 
(a)

(b)

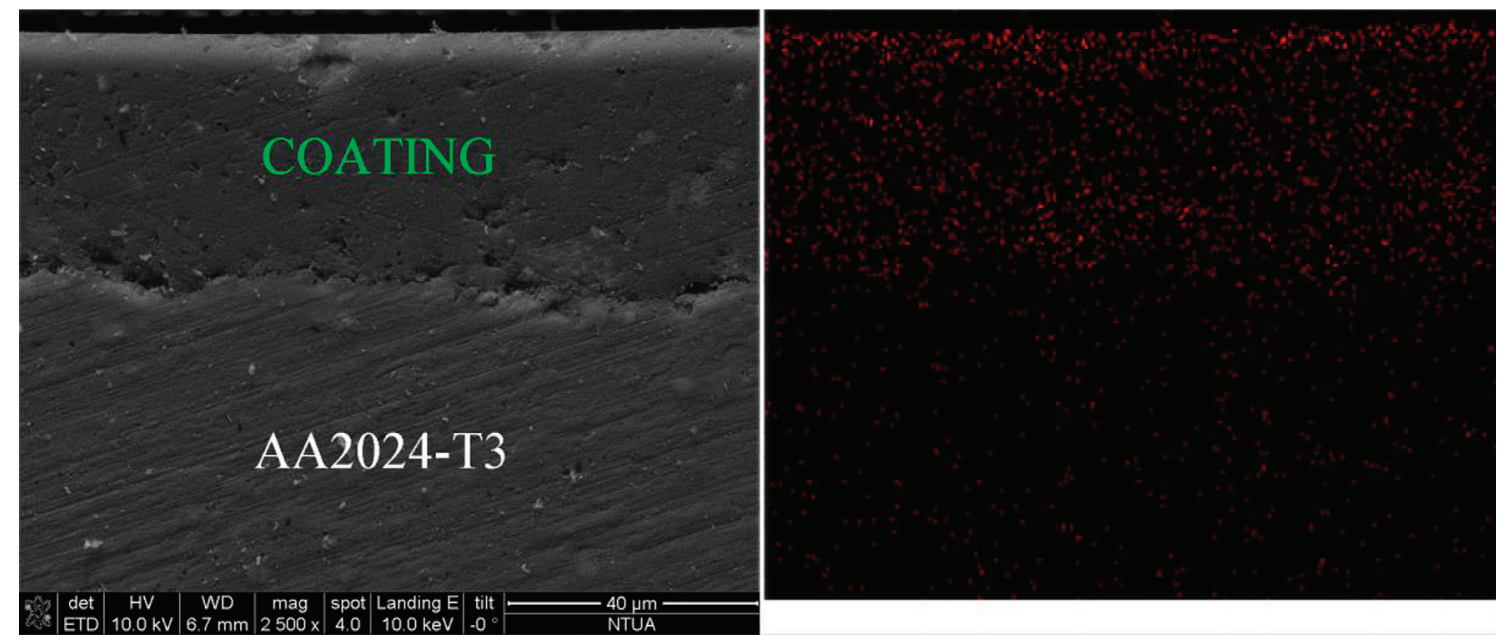

Figure 6. Cross-section mapping micrograph (a) and corresponding SEM image (b) of coating AA-coat-CeMo-MBT.

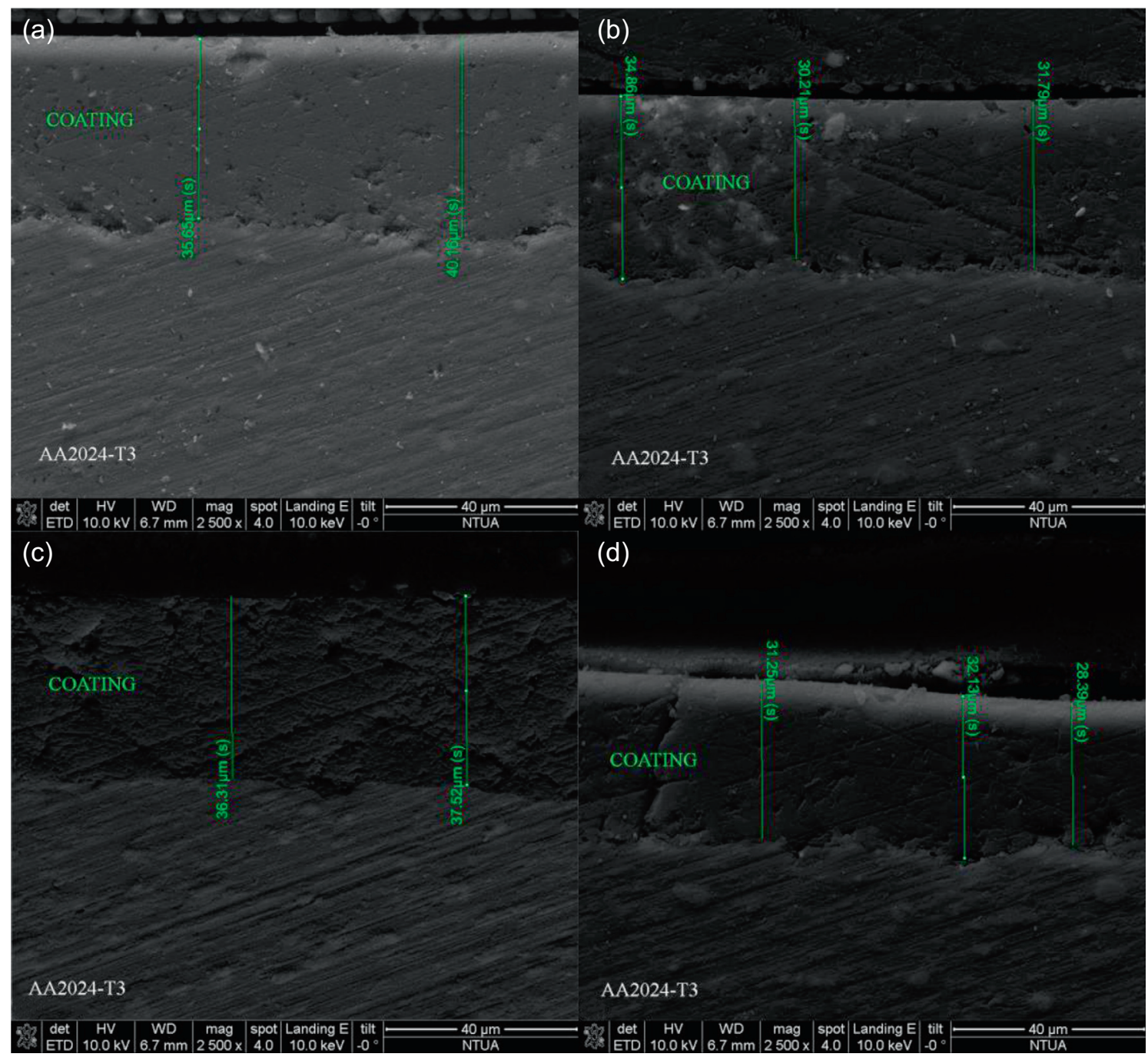

Figure 7. Cross-section SEM images of coatings: (a) AA-coat-CeMo-MBT, (b) AA-coat-CeMo, (c) AA-coat-MBT and (d) AA-coat. 


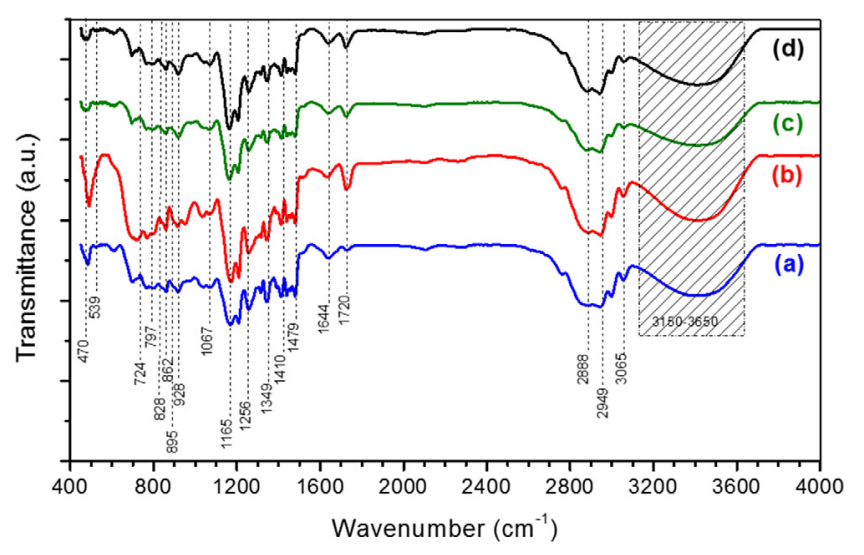

Figure 8. FT-IR spectra of coatings: (a) AA-coat-CeMo-MBT, (b) AA-coat-CeMo, (c) AA-coat-MBT and (d) AA-coat.

pH $5.95 \pm 0.05$. The SEM images of the surface morphology of the four coatings after their exposure at $50 \mathrm{mM} \mathrm{NaCl}$ solution for $72 \mathrm{~h}$ are depicted in Figure 9. Regarding the surface morphologies, it may be remarked that the coating including loaded nanocontainers does not show signs of corrosion (Figure 9a). On the other hand, both the coating including empty nanocontainers (Figure 9b) and the coating without nanocontainers present lots of cracks denoting the onset of corrosion (Figure 9d). Moreover, it can be seen that there are areas on the samples where the coating has been delaminated revealing the substrate. Finally, the coating containing only corrosion inhibitor exhibits a few cracks but no delaminated areas are visible (Figure 9c). The EDS analysis confirmed these observations demonstrating higher values of $\mathrm{Al}$ and $\mathrm{O}$ elements for the coatings AA-coat, AA-coat-MBT and AA-coat-CeMo compared to the coating including loaded nanocontainers (Table 5).

The corrosion resistance of the coatings with or without additives was studied by EIS. Figure 10 depicts the Bode (Figure 10a) and Nyquist (Figure 10b) plots of bare and coated AA 2024-T3 obtained after immersion into $50 \mathrm{mM}$ $\mathrm{NaCl}$ solution for $24 \mathrm{~h}$. The Bode diagram for the bare AA 2024-T3 demonstrates one time constant in the middlelow frequency range due to charge transfer processes based on corrosion activity $\mathrm{s}$ and a second time constant in the low frequency range that is ascribed to a diffusion limitation of the corrosion process [26]. The Bode plots for both the coatings AA-coat-CeMo and AA-coat-MBT present a relaxation time in the high frequency range that is assigned to the coating properties, a second time constant in the middle frequency domain that is related to the response of both the intermediate oxide layer as well as the Al-O-Si covalent bonds formed due to interaction between interfacial $\mathrm{Al}-\mathrm{OH}$ and $\mathrm{Si}-\mathrm{OH}$ groups, and a third time constant in the low frequencies that is attributed to the corrosion onset due to the pits that have been formed into the intermediate oxide layer [8]. The Bode plots for the coatings AA-coat-CeMo-MBT and AA-coat reveal two time constants, one in the high frequency domain due to the coating properties, and a second time constant in the middle frequencies due to the intermediate oxide layer and the Al-O-Si covalent bonds formed via interaction between
Table 4. FT-IR characteristic peaks of coatings.

\begin{tabular}{ll}
\hline Ranges $\left(\mathrm{cm}^{-1}\right)$ & \multicolumn{1}{c}{ Comment } \\
\hline $3150-3650$ & -OH groups \\
$2995-3050$ & C-H stretch in the epoxide \\
2949 & H-C-H asymmetric stretching \\
2888 & H-C-H asymmetric stretching \\
1720 & C=O \\
1644 & Bending absorption of water \\
1479 & Bending vibrations of the C-H bonds of the alkyl \\
& $\quad$ groups in the organic network \\
$1410-1470$ & C-C stretching deformation bands \\
1349 & C-O-C \\
$1270-1310$ & Symmetric C-C stretching deformation bands \\
1256 & Asymmetrical epoxy ring stretching bands \\
1200 & Strong Si-O-Si bands vibration \\
1165 & Si-O-Si asymmetric stretching vibration \\
1100 & Strong Si-O-Si bands vibration \\
1067 & Asymmetric C-O-C stretching vibration \\
928 & Asymmetrical epoxy ring stretching bands \\
895 & Molybdate ion \\
862 & Asymmetrical epoxy ring stretching bands \\
828 & Ce(OH) \\
797 & Symmetric Si-O-Si stretching vibrations \\
724 & Ce(OH) ${ }^{+2}$ \\
539 & Al-O-Si bending vibration \\
470 & Si-O-Si bending vibration \\
\hline
\end{tabular}

interfacial $\mathrm{Al}-\mathrm{OH}$ and $\mathrm{SiOH}$ groups. The Nyquist diagrams unequivocally confirm the presence of the aforementioned time constants for the corresponding coatings (Figure 10b). Considering Figure 10a it may be remarked that the coating including loaded nanocontainers (AA-coat-CeMo-MBT) demonstrates the best corrosion protection after exposure to corrosive environment for $24 \mathrm{~h}$ as it presents higher impedance values at low frequencies compared to the other three coatings.

Figure 11 illustrates the Bode and Nyquist plots of the coating after exposure to the aforementioned corrosive environment for $72 \mathrm{~h}$. Taking into account these plots, it can be mentioned that apart from AA-coat-CeMo-MBT, all the other three coatings demonstrate three time constants; one in the high frequency range that is ascribed to the barrier properties of the coatings, a second one in the middle frequencies that is assigned to the layer/substrate interface and a third one in the low frequency range that is attributed to corrosion process. On the other hand, the sample AA-coat-CeMo-MBT illustrates two relaxation times, one in the high frequency domain due to the coating properties, and a second time constant in the middle-low frequencies due to the intermediate oxide layer and the Al-O-Si covalent bonds formed via interaction between interfacial $\mathrm{Al}-\mathrm{OH}$ and $\mathrm{Si}-\mathrm{OH}$ groups. Estimating the aforementioned plots, it is evident that the samples AA-coat-CeMo-MBT present the highest impedance value in the low frequency range indicating improved protection against corrosion.

The EIS plots were fitted using equivalent circuits in order to understand the corrosion protective mechanism (Figure 12) and the obtained values are tabulated in Table 6. Regarding the fitting procedure, constant phase elements (CPE) were used instead of capacitances. This modification 

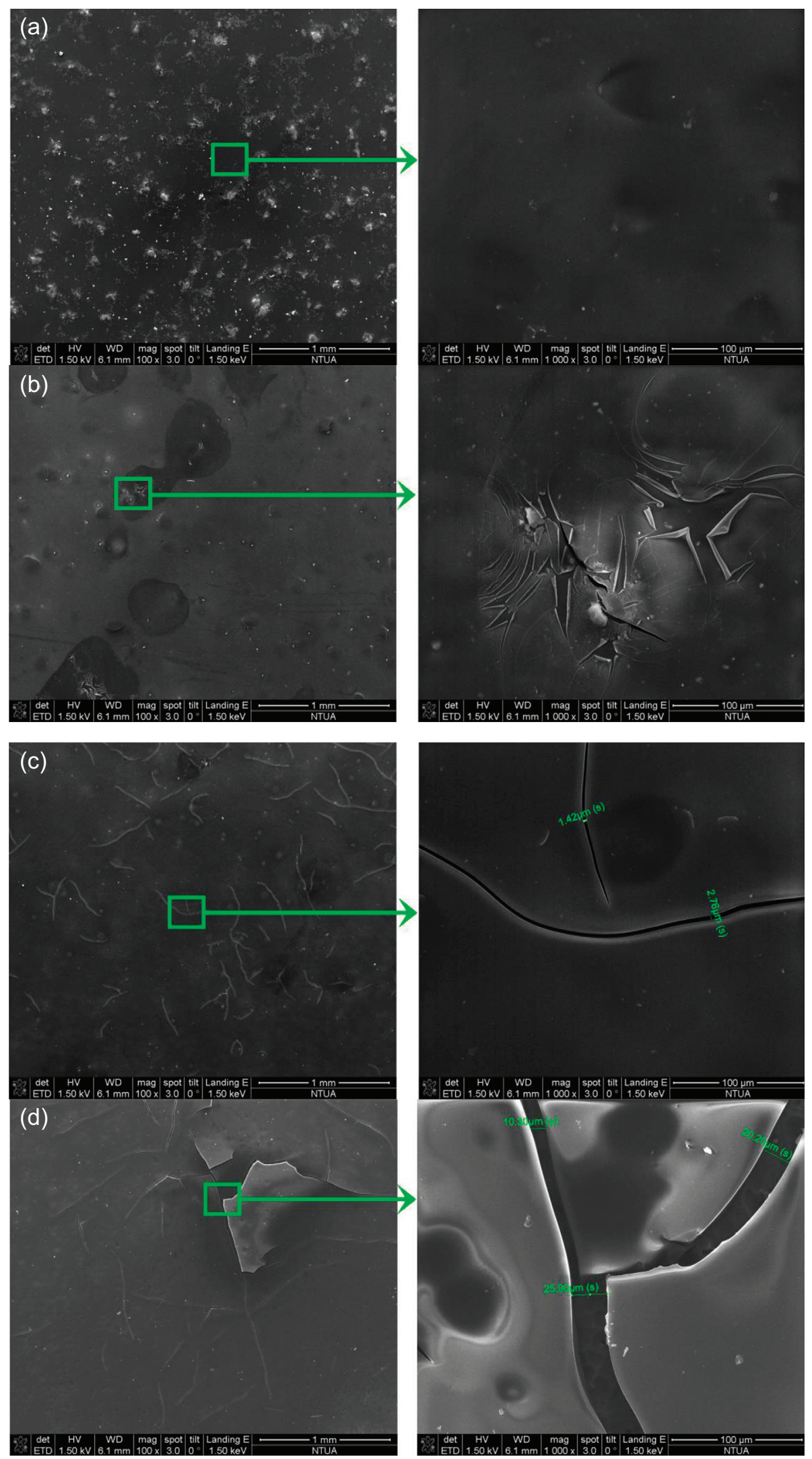

Figure 9. Surface morphology and EDX analysis of coatings: (a) AA-coat-CeMo-MBT, (b) AA-coat-CeMo, (c) AA-coat-MBT and (d) AA-coat, after their exposure at $50 \mathrm{mM} \mathrm{NaCl}$ solution for $72 \mathrm{~h}$. 
Table 5. Tabulated values of wt. $\%$ element concentration of the produced coatings after $72 \mathrm{~h}$ exposure to $50 \mathrm{mM} \mathrm{NaCl}$.

\begin{tabular}{lcccccc}
\hline & $\mathrm{C}$ & $\mathrm{O}$ & $\mathrm{Si}$ & $\mathrm{Mo}$ & $\mathrm{S}$ & $\mathrm{Ce}$ \\
\hline AA-coat & 43.74 & 30.49 & 18.34 & - & - & - \\
AA-coat-MBT & 47.21 & 29.18 & 18.80 & - & - & - \\
AA-coat-CeMo & 42.97 & 29.86 & 18.06 & 1.82 & - & 2.04 \\
AA-coat-CeMo-MBT & 49.85 & 23.27 & 18.54 & 3.73 & 0.41 & 2.29 \\
\hline
\end{tabular}

(a)
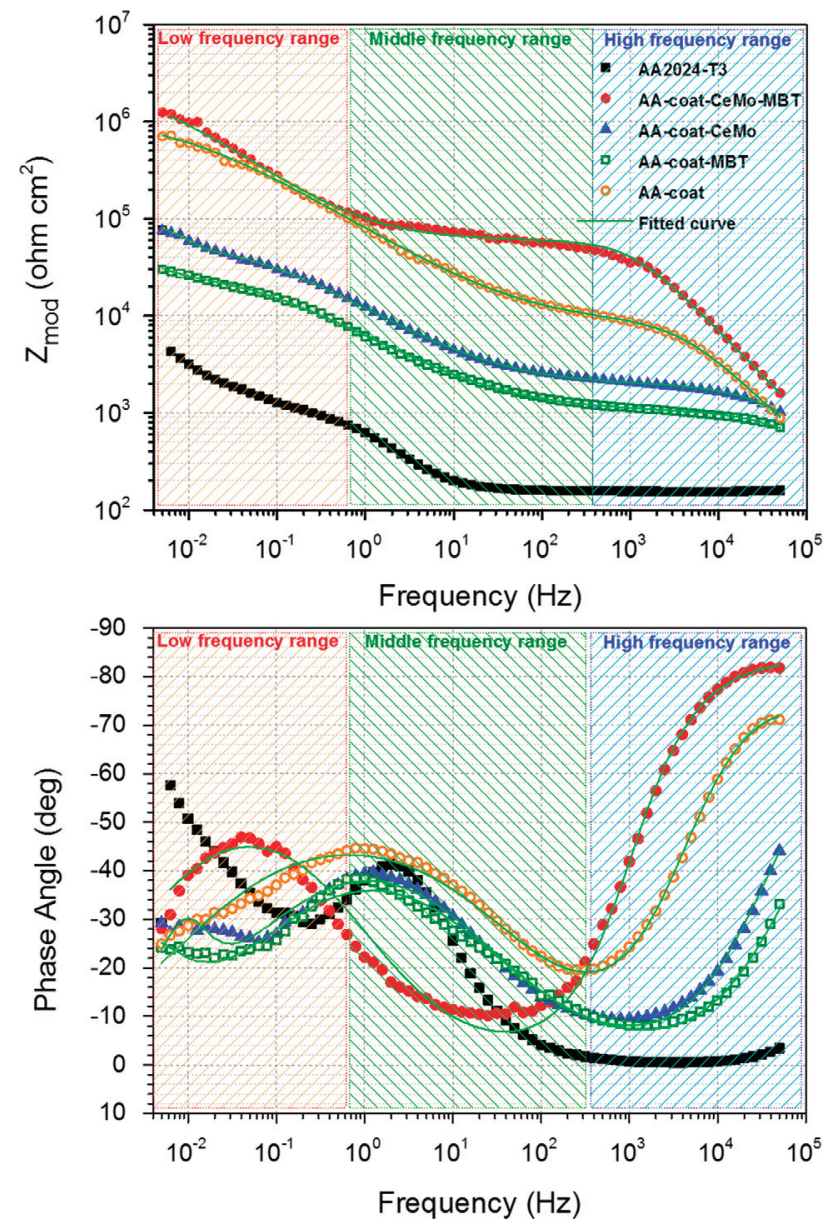

(b)

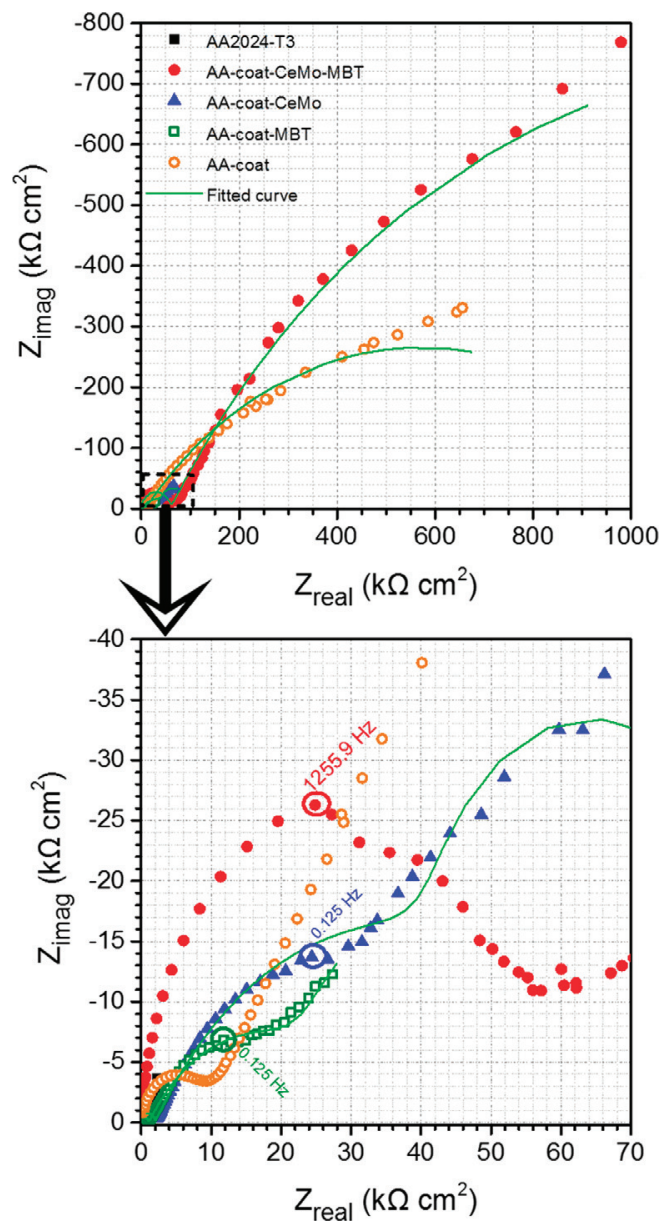

Figure 10. EIS (a) Bode plots and (b) Nyquist plots of coatings after exposure to $50 \mathrm{mM} \mathrm{NaCl}$ solution for $24 \mathrm{~h}$.

is obligatory in the case the phase shift of a capacitor is different from $-90^{\circ}$ [27]. The impedance of a R-CPE parallel association is given by:

$$
Z_{R-\mathrm{CPE}}=\frac{R}{1+R Y_{0}(j \omega)^{n}}
$$

where $Y_{0}$ is the admittance of the CPE and $n$ is the CPE exponent. It should be noted that constant phase elements correspond to a capacitor when the CPE exponent $(n)$ is one. Additionally, when $0.5<n<1$, CPE represents a nonideal capacitor. Finally, when $(n)$ equals to 0.5 , the CPE describes a diffusion process and represents a Warburg impedance [28]. Using the Cole-Cole approach together with
CPE, the capacitance can be calculated from the fittings by $[29,30]$ :

$$
C=\sqrt[n]{\frac{R Y_{0}}{R^{n}}}
$$

All the coatings demonstrated two time constants after exposure to corrosive environment for $3 \mathrm{~h}$; one in the high frequency range and a second one in the middle-low frequencies. Consequently, these impedance plots were fitted using the equivalent circuit of Figure 12a that includes the resistance and the capacitance of the coating $\left(R_{\text {coat }}-\mathrm{CPE}_{\text {coat }}\right)$ as well as the interface capacitance and the corresponding interface 
(a)
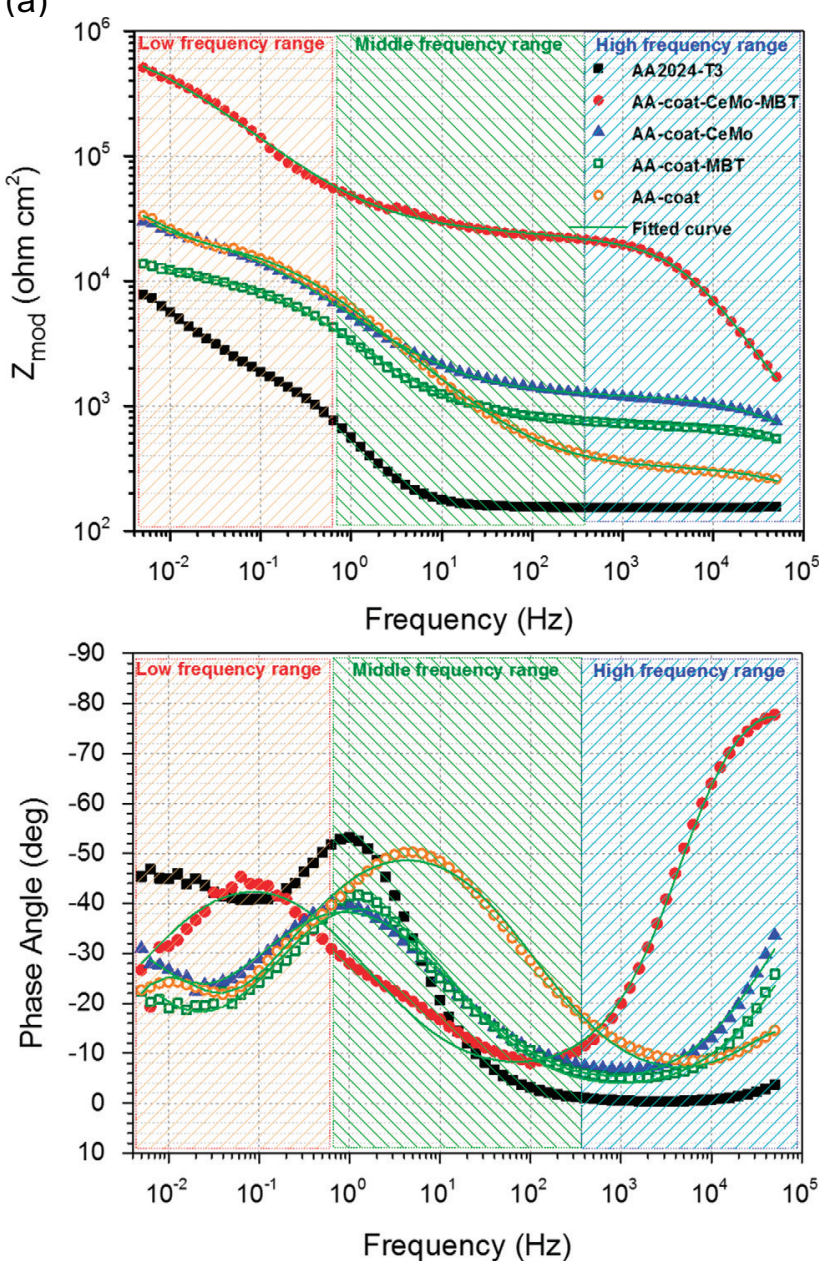

(b)
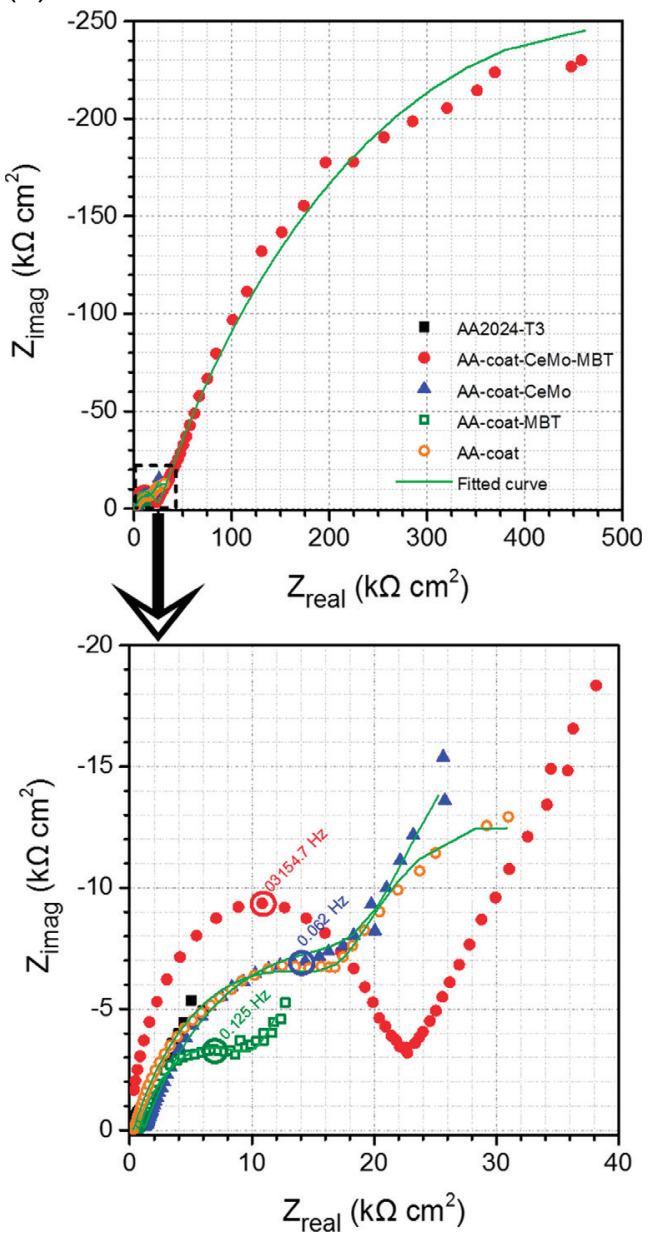

Figure 11. EIS (a) Bode plots and (b) Nyquist plots of coatings after exposure to $50 \mathrm{mM} \mathrm{NaCl}$ solution for $72 \mathrm{~h}$.

(a)

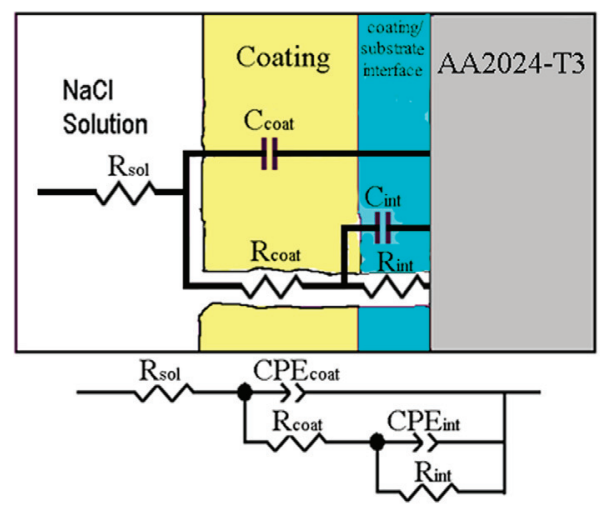

(b)

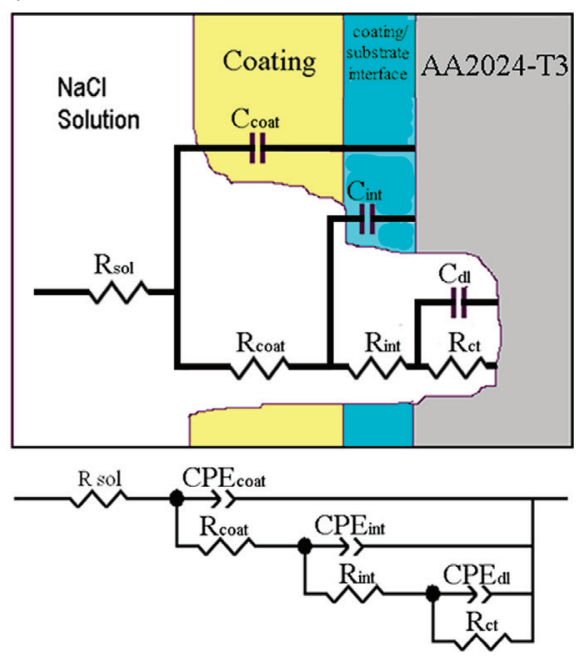

Figure 12. Equivalent circuits with (a) 5 and (b) 7 components used for numerical simulation of the EIS data of the coatings.

resistance $\left(R_{\text {int }}-\mathrm{CPE}_{\text {int }}\right)$. The resistance of the solution is illustrated as $\mathrm{R}_{\mathrm{sol}}$. As the immersion time elapses, the equivalent circuits for the AA-coat-MBT and AA-coat-CeMo coatings include seven components (Figure 12b) as it describes three time constants; the resistance and the capacitance of the coating $\left(R_{\text {coat }}-\mathrm{CPE}_{\text {coat }}\right)$, a second relaxation process 
Table 6. Fitting parameters according to equivalent circuits of Figure 12 after samples exposure to $50 \mathrm{mM} \mathrm{NaCl}$ solution.

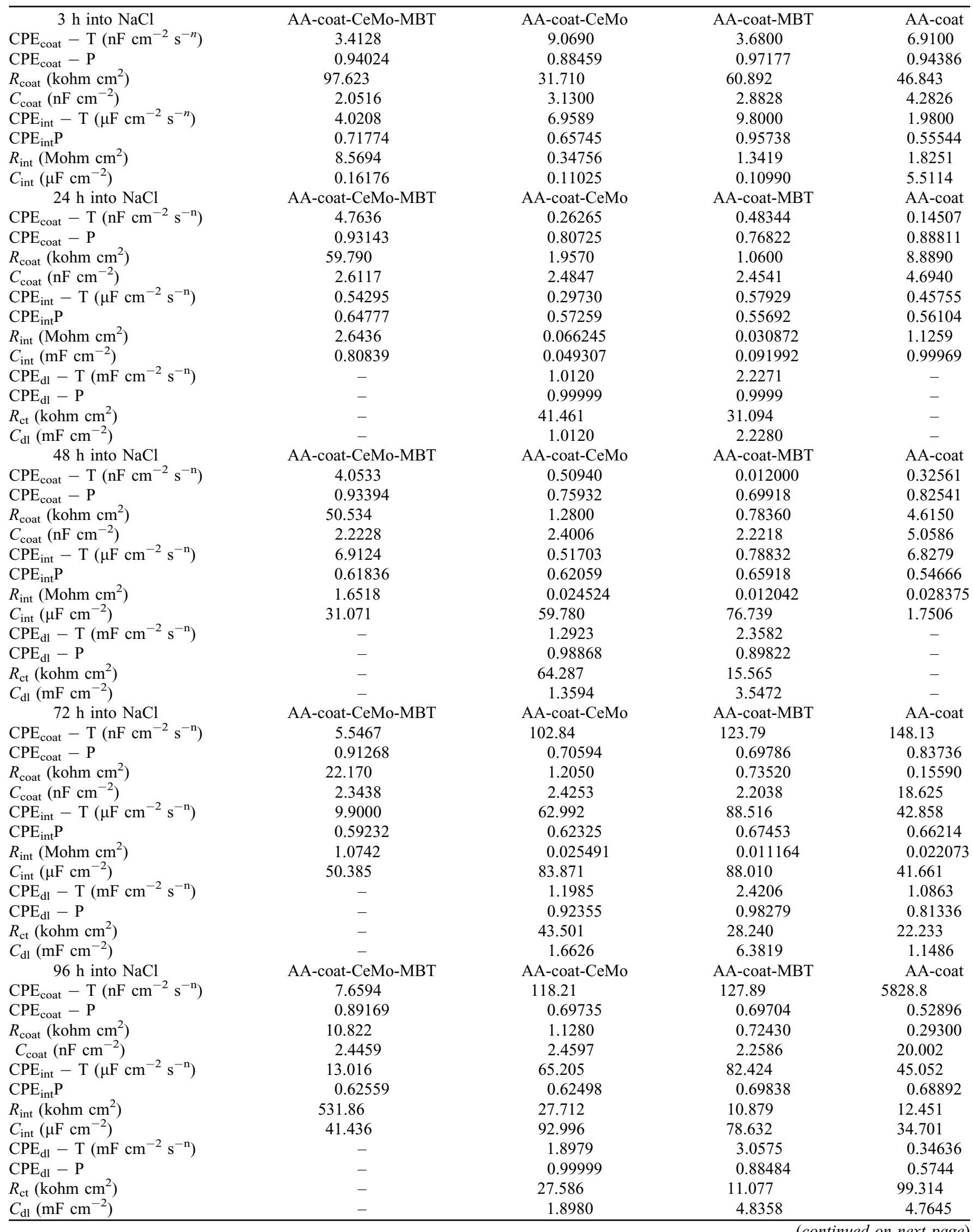


Table 6. (continued)

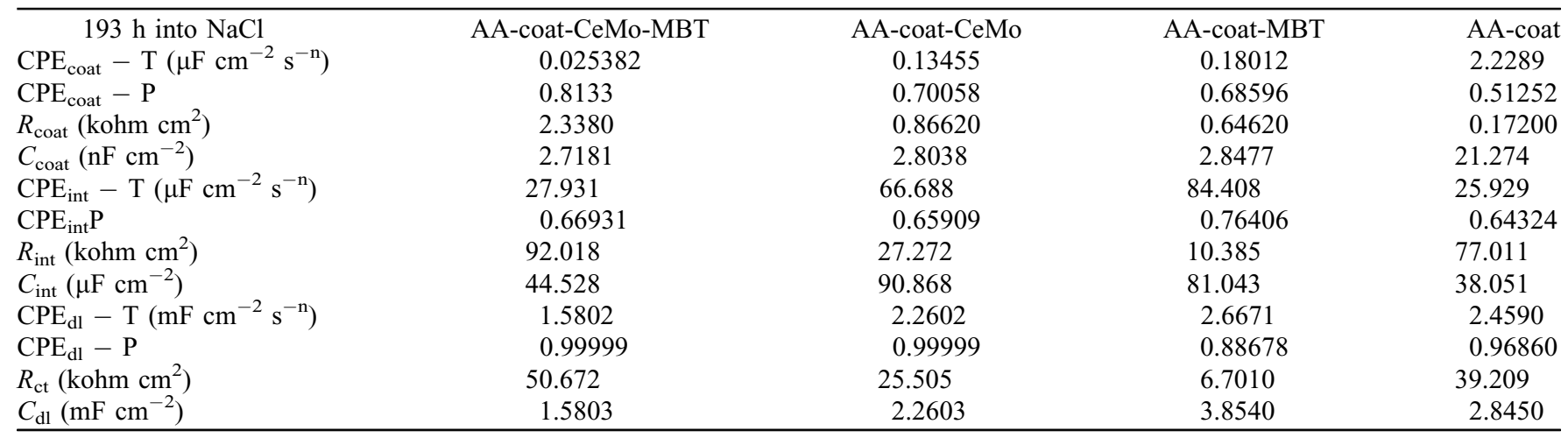

containing an interface capacitance and the corresponding interface resistance $\left(R_{\text {int }}-\mathrm{CPE}_{\text {int }}\right)$ and a third time constant including a charge transfer resistance and a double layer capacitance $\left(R_{\mathrm{ct}}-\mathrm{CPE}_{\mathrm{dl}}\right)$. The sample AA-coat for the first $24 \mathrm{~h}$ is simulated by an equivalent circuit that has the components of $R_{\text {coat }}-\mathrm{CPE}_{\text {coat }}$ and the components of $R_{\text {int }}-\mathrm{CPE}_{\text {int }}$, (Figure 12a). As the immersion time elapses, an additional time constant appeared in the low frequency domain and the appropriate equivalent circuit for the fitting is illustrated in Figure 12b. Finally, the sample AA-coat-CeMo-MBT is simulated by the equivalent circuit of Figure 12a for exposure times in corrosive environment up to $96 \mathrm{~h}$ and then, as the immersion time elapses, it is simulated by the circuit of Figure $12 \mathrm{~b}$.

The evolution of the mean values together with the corresponding error bars of the EIS fitting parameters $R_{\mathrm{ct}}, C_{\mathrm{dl}}, R_{\text {coat }}$, $C_{\text {coat }}, R_{\text {int }}$ and $C_{\text {int }}$ of all the coatings after their exposure to $50 \mathrm{mM} \mathrm{NaCl}$ solution is illustrated in Figure 13. Taking into account the $R_{\text {coat }}$ and $\mathrm{C}_{\text {coat }}$ values of all the coatings (Figures $13 \mathrm{a}, 13 \mathrm{~b})$ it is estimated that the coating including loaded nanocontainers (AA-coat-CeMo-MBT) has the best barrier properties as it demonstrates higher $R_{\text {coat }}$ values and lower $C_{\text {coat }}$ values compared to the other three coatings (Table 6). The same conclusions come out considering Figure $13 \mathrm{c}$, where it can be seen that the coating including loaded nanocontainers shows the highest $R_{\text {int }}$ values among all the coatings.

Regarding the estimating values of the double layer capacitance together with the charge transfer resistance of all the coatings (Figures 13e, 13f), it may be remarked that both the coatings AA-coat and AA-coat-CeMo-MBT reveal neither $C_{\mathrm{dl}}$ nor $R_{\mathrm{ct}}$ values for the first $48 \mathrm{~h}$ and $96 \mathrm{~h}$, respectively, due to the fact that there is no corrosion process. These results indicate that the two aforementioned coatings exhibit improved protection against corrosion. As the immersion time elapses up to $193 \mathrm{~h}$, the coating including loaded nanocontainers (AA-coatCeMo-MBT) illustrates the highest $R_{\mathrm{ct}}$ value together with lowest $C_{\mathrm{dl}}$ value (Table 6). It is important to mention that high $R_{\mathrm{ct}}$ values mean high resistance to the corrosion process and that low $C_{\mathrm{dl}}$ values correspond to low corrosion reaction area [31].

\subsection{Corrosion inhibition mechanism}

Two main types of corrosion appeared on the AA 2024-T3; pitting and intergranular corrosion.
Pitting corrosion is observed in aerated solutions of halides in the passive region of $\mathrm{pH}$. In aerated $\mathrm{NaCl}$ aqueous solutions, the anodic reaction is accelerated by chloride ions, while the cathodic reaction is oxygen reduction. Weak points of the oxide or hydroxide passivating film of the AA2024-T3 are intitiated due to pitting corrosion, according to the following anodic reactions (dissolution of $\mathrm{Al}$ ):

$$
\begin{gathered}
\mathrm{Al} \rightarrow \mathrm{Al}^{+3}+3 \mathrm{e}^{-} \\
\mathrm{Al}^{+3}+3 \mathrm{H}_{2} \mathrm{O} \rightarrow \mathrm{Al}(\mathrm{OH})_{3}+3 \mathrm{H}^{+}
\end{gathered}
$$

Taking into consideration the neutral solution, the consumption of hydroxide ions at the anodic sites can make the $\mathrm{pH}$ more acidic, in the range of $3-4$, followed by migration of chloride ions [32]. These ions facilitate the anodic reaction and form aluminium chlorides which are hydrolysed and give aluminium hydroxides and acids shifting the $\mathrm{pH}$ to acidic values according to the following reaction:

$$
\mathrm{AlCl}_{3}+3 \mathrm{H}_{2} \mathrm{O} \rightarrow \mathrm{Al}(\mathrm{OH})_{3}+3 \mathrm{HCl}
$$

On the other hand, the reduction reactions that occur in acidic aqueous solution are the reduction of water and the reduction of oxygen [33, 34]:

$$
\begin{gathered}
2 \mathrm{H}_{3} \mathrm{O}^{+}+2 \mathrm{e}^{-} \rightarrow \mathrm{H}_{2}+2 \mathrm{H}_{2} \mathrm{O} \\
\mathrm{O}_{2}+2 \mathrm{H}^{+}+2 \mathrm{e}^{-} \rightarrow \mathrm{H}_{2} \mathrm{O}_{2} \\
\mathrm{H}_{2} \mathrm{O}_{2}+2 \mathrm{H}^{+}+2 \mathrm{e}^{-} \rightarrow 2 \mathrm{H}_{2} \mathrm{O}
\end{gathered}
$$

It may be remarked that the presence of oxygen and/or another oxidant is essential for pitting and that the cathodic sites are frequently more alkaline due to the local formation of hydroxides.

Regarding an oxygenated chloride solution, it can be mentioned that pit initiation is generally controlled by the cathodic reaction kinetics. Moreover, pit propagation requires a sufficient $\mathrm{Cl}^{-}$concentration in the solution contained within the pit, because the formation of a concentrated $\mathrm{AlCl}_{3}$ solution within active pits is assigned to $\mathrm{Cl}^{-}$[32]. Furthermore, in aluminium-copper-magnesium alloys (2XXX), thermal treatments 

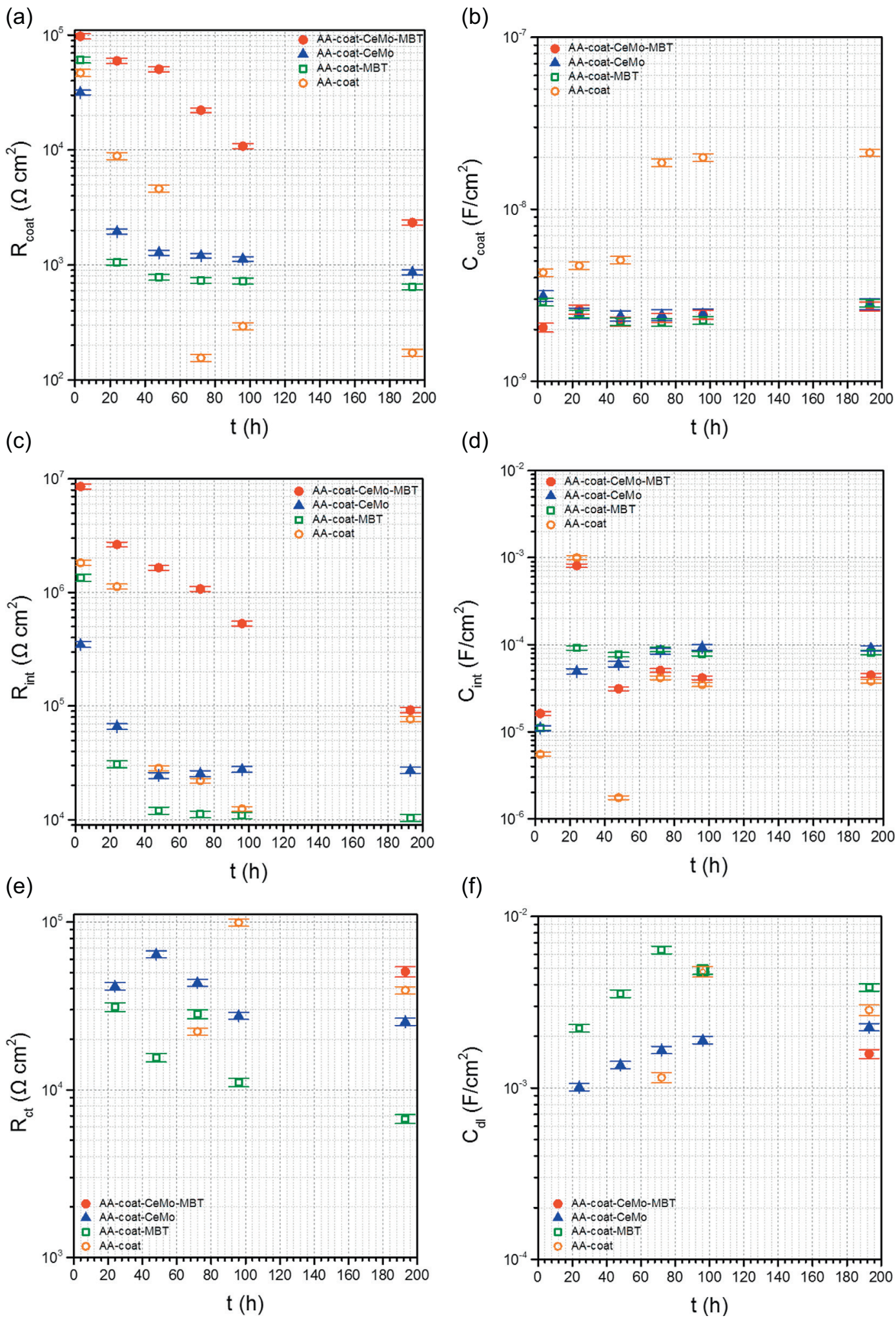

Figure 13. The evolution of the EIS fitting parameters of all the coatings after their exposure to $50 \mathrm{mM} \mathrm{NaCl} \mathrm{solution:} \mathrm{(a)} R_{\text {coat }}$, (b) $C_{\text {coat }}$, (c) $R_{\text {int }}$ (d) $C_{\text {int }}$, (e) $R_{\mathrm{ct}}$ and (f) $C_{\mathrm{dl}}$.

can cause selective grain boundary precipitation resulting in the appearance of intergranular corrosion susceptibility. In particular, regarding the $\mathrm{AA} 2024-\mathrm{T} 3, \mathrm{CuAl}_{2}$ precipitates accelerate the corrosion of a depleted zone adjacent to the grain boundary due to the fact that these precipitates are nobler than the matrix and act as cathodes [32]. 
(a)

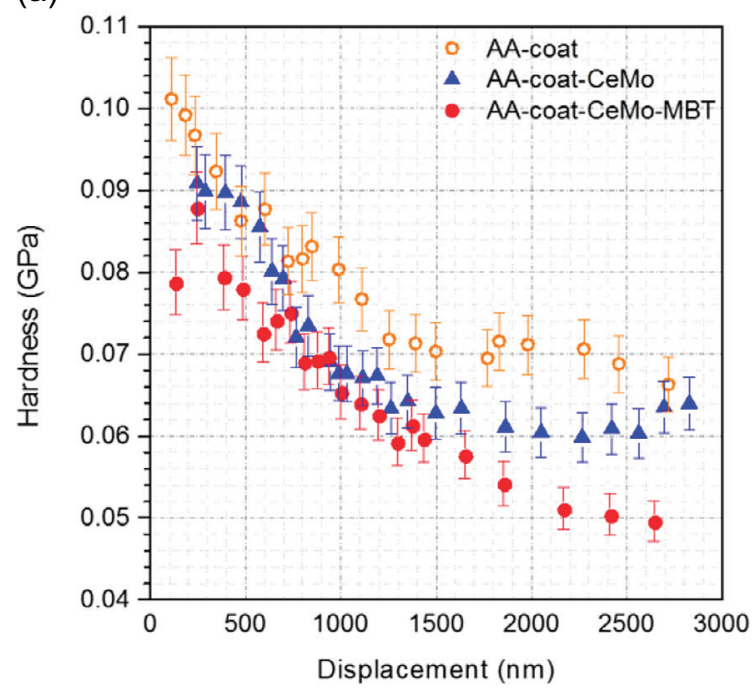

(b)

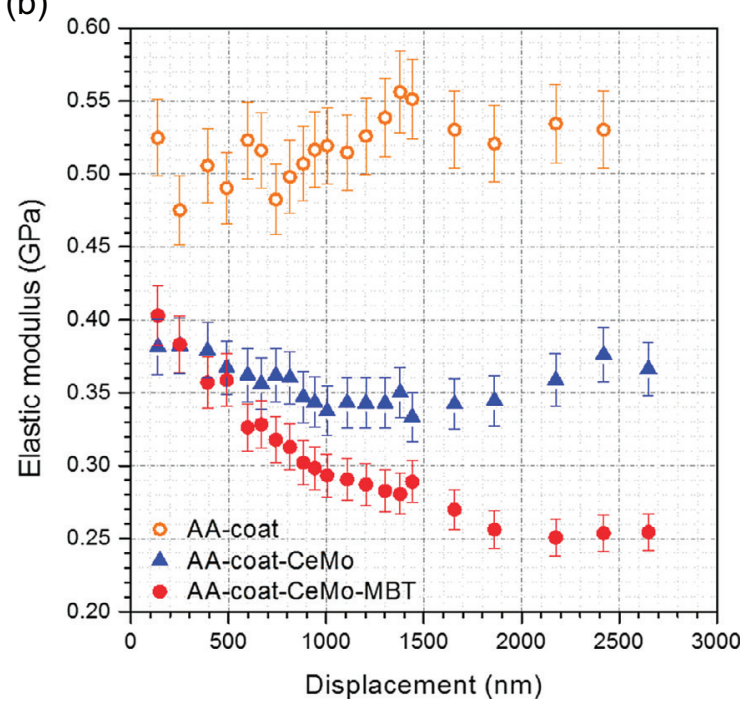

Figure 14. Nanomechanical properties (a) hardness $(H)$ and (b) elastic modulus $(E)$ of coatings.

The improved properties of the AA-coat-CeMo-MBT coating against corrosion can be ascribed to the presence of the encapsulated inhibitor into the containers as well as the enhanced coherence of the coating. The encapsulation of the inhibitor into the containers (AA-coat-CeMo-MBT) instead of its addition into the coating (AA-coat-MBT) probably impair the coating coherence to a lesser degree resulting in improved corrosion protection properties. Furthermore, it is assumed that the release of the inhibitor from the containers after the onset of corrosion results, in the case of AA 2024$\mathrm{T} 3$, in the dissolution inhibition of the adjacent anodic materials surrounding the $\mathrm{Al}(\mathrm{Fe}, \mathrm{Mn}, \mathrm{Mg} / \mathrm{Si}$ ) (Table 1) intermetallic particles through the formation of stable complexes between the metals and the thiol groups [35, 36]. Except for the MBT inhibitor, the shell of the CeMo containers acts itself as corrosion inhibitor due to its dissolution to $\mathrm{MoO}_{4}{ }^{-2}$ and cerium ions in corrosive environment. Furthermore, in aqueous molybdate solution with a $\mathrm{pH}$ roughly 6 , condensation of $\mathrm{MoO}_{4}{ }^{-2}$ ions into heptamolybdate (paramolybdate) polyanion occurs [37] according to the following reaction:

$$
7\left[\mathrm{MoO}_{4}\right]^{-2}+8 \mathrm{H}^{+} \leftrightarrow\left[\mathrm{Mo}_{7} \mathrm{O}_{24}\right]^{-6}+4 \mathrm{H}_{2} \mathrm{O}
$$

Moreover, polyanions such as $\left[(\mathrm{OH})_{4} \mathrm{OMo}-\mathrm{O}-\right.$ $\left.\mathrm{MoO}(\mathrm{OH})_{4}\right]^{-2},\left[\mathrm{Mo}_{8} \mathrm{O}_{26}\right]^{-4},\left[\mathrm{Mo}_{6} \mathrm{O}_{21}\right]^{-6},\left[\mathrm{MoO}(\mathrm{OH})_{5}\right]^{-}$and $\left[\mathrm{MoO}_{3}(\mathrm{OH})\right]^{-}$can also exist $[18,38]$. Subsequently, considering that the aforementioned experiments were performed using corrosive solutions with $\mathrm{pH}=5.95 \pm 0.05$, the polymolybdate ions could be adsorbed onto the positive charged metal surface of AA resulting in its protection of chloride penetration [39].

On the contrary, it may be remarked that the effectiveness of cerium cations as corrosion inhibitors is doubtless. The reason is that the $\mathrm{pH}$ of the used corrosive solutions is not alkaline and the formation of $\mathrm{Ce}(\mathrm{OH})_{3}$ film on the cathodic sites of the metal alloy is not feasible [40, 41]. Nevertheless, a film based on $\mathrm{Ce}(\mathrm{OH})_{4}$ is precipitated onto the aluminium alloy, acting as a protective coating against aluminium corrosion. Regarding the reaction (7) the oxygen reduction produces $\mathrm{H}_{2} \mathrm{O}_{2}$ that can be further reduced resulting in the local formation of $\mathrm{OH}^{-}$as well as to the oxidation of $\mathrm{Ce}^{+3}$ to $\mathrm{Ce}^{+4}$. Consequently, $\mathrm{Ce}(\mathrm{OH})_{4}$ is formed according to the following reactions:

$$
\begin{gathered}
\mathrm{H}_{2} \mathrm{O}_{2}+2 \mathrm{e}^{-} \rightarrow 2 \mathrm{OH}^{-} \\
\mathrm{Ce}^{+3}+\mathrm{OH}^{-}+\frac{1}{2} \mathrm{H}_{2} \mathrm{O}_{2} \rightarrow \mathrm{Ce}(\mathrm{OH})_{2}^{+2} \\
\mathrm{Ce}(\mathrm{OH})_{2}^{+2}+2 \mathrm{OH}^{-} \rightarrow \mathrm{Ce}(\mathrm{OH})_{4}
\end{gathered}
$$

As reported in the literature the precipitation of $\mathrm{Ce}(\mathrm{OH})_{4}$ can result even at $\mathrm{pH}=2.9[41,42]$. Thus, it may be mentioned that the cerium ions can inhibit the aluminium corrosion in a $\mathrm{NaCl}$ solution.

\subsection{Nanomechanical properties}

The nanomechanical properties (namely $H$ and $E$ ) of the coatings are presented in Figure 14. The incorporation of nanocontainers (with or without inhibitor) affects the mechanical integrity of the coatings, revealing a clear mechanical degradation of sol-gel coating; while $H$ is slightly decreased, samples exhibit greater deviation in $E$ values.

The ratio of hardness to elastic modulus is of significant interest in tribology. Higher stresses are expected in high $H / E$, hard materials, and high stress concentrations develop towards the indenter tip, whereas in the case of low $H / E$, soft materials, the stresses are lower and are distributed more evenly across the cross-section of the material [43, 44]. The high ratio of hardness to elastic modulus $(H / E)$ is indicative of good wear resistance in a disparate range of materials: ceramic, metallic and polymeric (for example: c-BN, tool steel, nylon, respectively), which are equally effective in resisting attrition for their particular intended application. In Figure 15, the change of $H / E$ slope reveals that the addition 


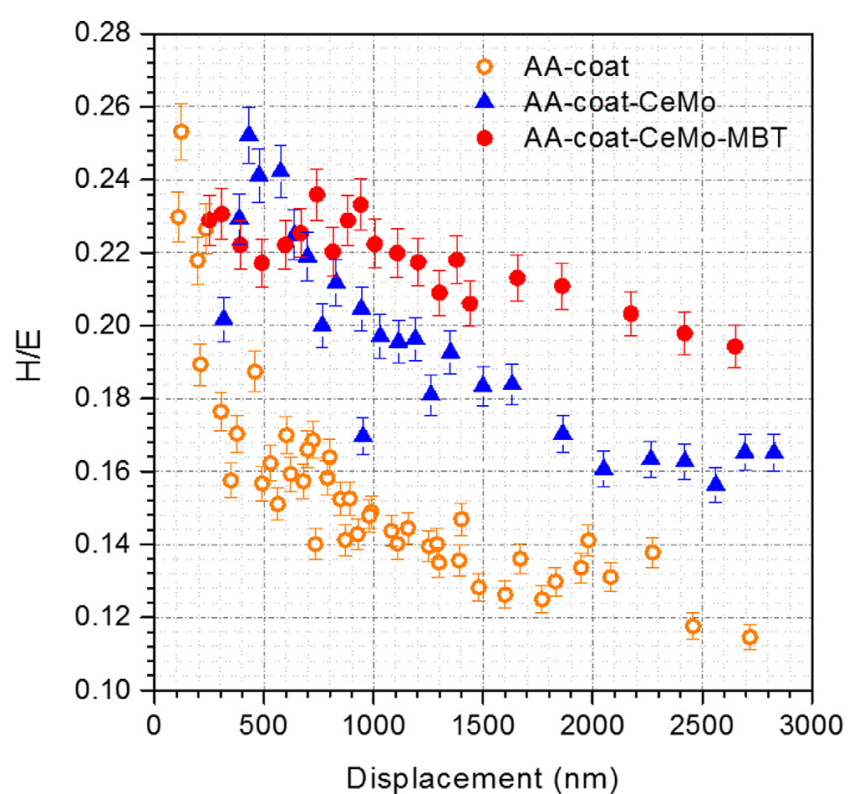

Figure 15. Correlation of $H / E$ ratio to displacement, for all the coatings.

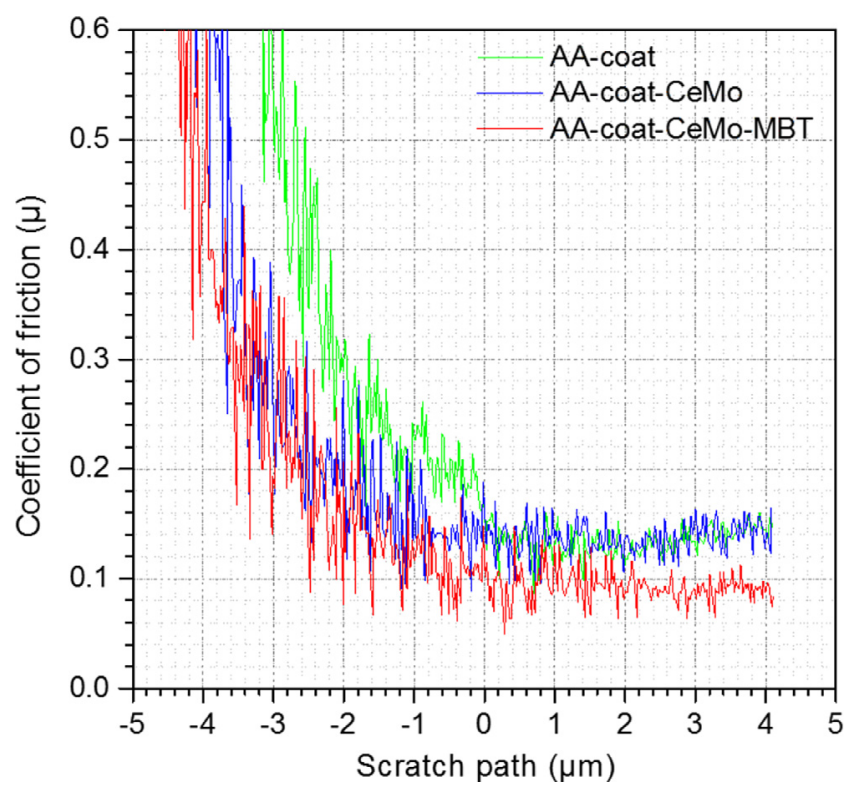

Figure 16. Coefficient of friction for all coatings through nanoscratch testing.

of nanocontainers empty or loaded with inhibitor strengthens (increase of wear resistance) the coating after $\sim 300 \mathrm{~nm}$ of displacement, having no significant impact on surface region $(0-300 \mathrm{~nm})$, where all coatings exhibited similar (increased) $H / E$ ratio.

In Figure 16, coefficients of friction for all coatings are presented. Incorporation of nanocontainers decreases the coefficients of friction, for the whole scratch path especially for the case of AA-coat-CeMo-MBT system; however, when the tip further penetrates the sample, the behaviour is almost identical for AA-coat and AA-coat-CeMo samples. In case of AA-coat-CeMo-MBT system, the decrease of coefficient of friction almost at the end of scratch path is well addressed in line with $H / E$ behaviour (Figure 15).

\section{Conclusions}

A system including sol-gel coating based on GPTMS as well as nanocontainers incorporated into the coating was studied for the protection of AA 2024-T3 against corrosion. The nanocontainers consist of cerium molybdate that were either empty or loaded with corrosion inhibitor MBT. Several coatings were synthesized in the presence or absence of nanocontainers. The results reveal that the produced coatings protect the metal alloy against corrosion, but be that as it may, the presence of nanocontainers loaded with MBT into the coating improves its corrosion protective properties demonstrating higher impedance values at the low frequency range compared to the other coatings. Furthermore, apart from the coating including loaded containers, all the other coatings presented cracks on their surface after their exposure to corrosive environment indicating reduced corrosion properties protection. The evaluation on the nano-mechanical properties of the system proved that the addition of nanocontainers empty or loaded with corrosion inhibitor strengthens the coating and decreases the coefficient of friction which should result in an increase of wear resistance. The enhanced corrosion protection properties of the coatings including nanocontainers loaded with MBT can be attributed to either the increase coherence of the coating or the simultaneously inhibition action of cerium and molybdate ions together with the corrosion inhibitor MBT. However, additional experiments should be conducted in future studies in respect of reducing the time and curing temperature of the coatings production. Moreover, several types of nanocontainers loaded with different corrosion inhibitors will be incorporated into the aforementioned films. Finally, the produced coatings will be applied in various metal alloys in order their protection against corrosion to be further investigated.

\section{References}

1. M. Oubaha, P.C.R. Varma, B. Duffy, Z.M. Gasem, S.J. Hinder, Development of a novel hybrid aluminum-based sol-gel materials: application to the protection of AA2024-T3 alloys in alkaline environment, Advances in Materials Physics and Chemistry 04 (2014) 75-84.

2. J.R. Davis, Corrosion of aluminium and aluminium alloys, ASM International, Materials Park, OH, 1999.

3. C.G. Alimba, V. Dhillon, A.A. Bakare, M. Fenech, Genotoxicity and cytotoxicity of chromium, copper, manganese and lead, and their mixture in WIL2-NS human B lymphoblastoid cells is enhanced by folate depletion, Mutation Research Genetic Toxicology and Environmental Mutagenesis 798-799 (2016) 35-47.

4. E.D. Mekeridis, I.A. Kartsonakis, G.C. Kordas, Multilayer organic-inorganic coating incorporating $\mathrm{TiO}_{2}$ nanocontainers loaded with inhibitors for corrosion protection of AA2024-T3, Progress in Organic Coatings 73 (2012) 142-148. 
5. O. Lev, Z. Wu, S. Bharathi, V. Glezer, A. Modestov, J. Gun, L. Rabinovich, S. Sampath, Sol-gel materials in electrochemistry, Chemistry of Materials 9 (1997) 2354-2375.

6. Z. Tian, H. Shi, F. Liu, S. Xu, E.-H. Han, Inhibiting effect of 8-hydroxyquinoline on the corrosion of silane-based sol-gel coatings on AA2024-T3, Progress in Organic Coatings 82 (2015) 81-90.

7. M.L. Zheludkevich, K.A. Yasakau, S.K. Poznyak, M.G.S. Ferreira, Triazole and thiazole derivatives as corrosion inhibitors for AA2024 aluminium alloy, Corrosion Science 47 (2005) 3368-3383.

8. M. Gharagozlou, R. Naderi, Z. Baradaran, Effect of synthesized $\mathrm{NiFe}_{2} \mathrm{O}_{4}$-silica nanocomposite on the performance of an ecofriendly silane sol-gel coating, Progress in Organic Coatings 90 (2016) 407-413.

9. D. Snihirova, S.V. Lamaka, P. Taheri, J.M.C. Mol, M.F. Montemor, Comparison of the synergistic effects of inhibitor mixtures tailored for enhanced corrosion protection of bare and coated AA2024-T3, Surface and Coatings Technology 303 (2016) 342-351.

10. I. Recloux, M. Mouanga, M.-E. Druart, Y. Paint, M.-G. Olivier, Silica mesoporous thin films as containers for benzotriazole for corrosion protection of 2024 aluminium alloys, Applied Surface Science 346 (2015) 124-133.

11. M.L. Zheludkevich, S.K. Poznyak, L.M. Rodrigues, D. Raps, T. Hack, L.F. Dick, T. Nunes, M.G.S. Ferreira, Active protection coatings with layered double hydroxide nanocontainers of corrosion inhibitor, Corrosion Science 52 (2010) 602-611.

12. I.A. Kartsonakis, A.C. Balaskas, G.C. Kordas, Influence of cerium molybdate containers on the corrosion performance of epoxy coated aluminium alloys 2024-T3, Corrosion Science 53 (2011) 3771-3779.

13. E.D. Mekeridis, I.A. Kartsonakis, G.S. Pappas, G.C. Kordas, Release studies of corrosion inhibitors from cerium titanium oxide nanocontainers, Journal of Nanoparticle Research 13 (2010) 541-554.

14. C.A. Charitidis, Nanomechanical and nanotribological properties of carbon-based thin films: a review, International Journal of Refractory Metals and Hard Materials 28 (2010) 51-70.

15. W.C. Oliver, G.M. Pharr, An improved technique for determining hardness and elastic modulus using load and displacement sensing indentation experiments, Journal of Materials Research 7 (2011) 1564-1583.

16. I.A. Kartsonakis, S.G. Stanciu, A.A. Matei, R. Hristu, A. Karantonis, C.A. Charitidis, A comparative study of corrosion inhibitors on hot-dip galvanized steel, Corrosion Science (2016).

17. I.A. Kartsonakis, D.A. Dragatogiannis, E.P. Koumoulos, A. Karantonis, C.A. Charitidis, Corrosion behaviour of dissimilar friction stir welded aluminium alloys reinforced with nanoadditives, Materials \& Design 102 (2016) 56-67.

18. K.C. Emregül, A.A. Aksüt, The effect of sodium molybdate on the pitting corrosion of aluminum, Corrosion Science 45 (2003) 2415-2433.

19. K.A. Yasakau, J. Tedim, M.L. Zheludkevich, R. Drumm, M. Shem, M. Wittmar, M. Veith, M.G.S. Ferreira, Cerium molybdate nanowires for active corrosion protection of aluminium alloys, Corrosion Science 58 (2012) 41-51.

20. I.A. Kartsonakis, G. Kordas, Synthesis and characterization of cerium molybdate nanocontainers and their inhibitor complexes, Journal of the American Ceramic Society 93 (2010) 65-73.
21. I.A. Kartsonakis, I.L. Danilidis, G.S. Pappas, G.C. Kordas, Encapsulation and release of corrosion inhibitors into titania nanocontainers, Journal of Nanoscience and Nanotechnology 10 (2010) 5912-5920.

22. H. Bei, E.P. George, J.L. Hay, G.M. Pharr, Influence of indenter tip geometry on elastic deformation during nanoindentation, Physical Review Letters 95 (2005) 045501.

23. L. Wang, C. Zhang, H. Xie, W. Sun, X. Chen, X. Wang, Z. Yang, G. Liu, Calcium alginate gel capsules loaded with inhibitor for corrosion protection of downhole tube in oilfields, Corrosion Science 90 (2015) 296-304.

24. P. Innocenzi, G. Brusatin, M. Guglielmi, R. Bertani, New synthetic route to (3-glycidoxypropyl)trimethoxysilane-based hybrid organic-inorganic materials, Chemistry of Materials 11 (1999) 1672-1679.

25. I. Bobos, Kaolinite to halloysite-7 $\AA$ transformation in the kaolin deposit of São Vicente de Pereira, Portugal, Clays and Clay Minerals 49 (2001) 596-607.

26. S.V. Lamaka, M.L. Zheludkevich, K.A. Yasakau, M.F. Montemor, M.G.S. Ferreira, High effective organic corrosion inhibitors for 2024 aluminium alloy, Electrochimica Acta 52 (2007) 7231-7247.

27. C.H. Hsu, F. Mansfeld, Technical note: concerning the conversion of the constant phase element parameter $\mathrm{Y} 0$ into a capacitance, Corrosion 57 (2001) 747-748.

28. G. Kong, L. Lingyan, J. Lu, C. Che, Z. Zhong, Corrosion behavior of lanthanum-based conversion coating modified with citric acid on hot dip galvanized steel in aerated $1 \mathrm{~m} \mathrm{NaCl}$ solution, Corrosion Science 53 (2011) $1621-1626$.

29. K.S. Cole, Dispersion and absorption in dielectrics II. Direct current characteristics, The Journal of Chemical Physics 10 (1942) 98.

30. J.R. Macdonald, E. Barsoukov, Fundamentals of impedance spectroscopy, in: E. Barsoukov, J.R. Macdonald (Eds.), Impedance spectroscopy theory, experiment, and applications, John Wiley and Sons, USA, 2005, pp. 13-20.

31. S. Shen, Y. Zuo, X. Zhao, The effects of 8-hydroxyquinoline on corrosion performance of a Mg-rich coating on AZ91D magnesium alloy, Corrosion Science 76 (2013) 275-283.

32. R. Winston Revie, Uhlig's corrosion handbook, 2nd edn, John Wiley and Sons, New York, 2000, 694-704.

33. S.J. Kelly, D.W. Shoesmith, R.G. Buchheit, Electrochemical thermodynamics and kinetics of relevance to corrosion, in: P.A. Schweitzer (Ed.), Electrochemical techniques in corrosion science and engineering, Marcel Dekker, Inc., New York, 2002, pp. 9-54.

34. X.G. Zhang, Electrochemical thermodynamics and kinetics, in: X.G. Zhang (Ed.), Corrosion and electrochemistry of zinc, Springer Science+ Business Media, Llc., New York, 1996, pp. 19-64.

35. M. Plawecka, D. Snihirova, B. Martins, K. Szczepanowicz, P. Warszynski, M.F. Montemor, Self healing ability of inhibitorcontaining nanocapsules loaded in epoxy coatings applied on aluminium 5083 and galvanneal substrates, Electrochimica Acta 140 (2014) 282-293.

36. U. Donatus, G.E. Thompson, X. Zhou, J. Wang, A. Cassell, K. Beamish, Corrosion susceptibility of dissimilar friction stir welds of AA5083 and AA6082 alloys, Materials Characterization 107 (2015) 85-97.

37. A. Earnshaw, N.N. Greenwood, Chromium, molybdenum and tungsten, in: N.N. Greenwood, A. Earnshaw (Eds.), Chemistry 
of the elements, Butterworth-Heinemann, Oxford, 1998, pp. 1022-1039.

38. G. Mu, X. Li, Q. Qu, J. Zhou, Molybdate and tungstate as corrosion inhibitors for cold rolling steel in hydrochloric acid solution, Corrosion Science 48 (2006) 445-459.

39. C.N. Panagopoulos, E.P. Georgiou, A.G. Gavras, Corrosion and wear of 6082 aluminum alloy, Tribology International 42 (2009) 886-889.

40. M. Amra, K. Ranjbar, R. Dehmolaei, Mechanical properties and corrosion behavior of $\mathrm{CeO}_{2}$ and $\mathrm{SiC}$ incorporated $\mathrm{Al} 5083$ alloy surface composites, Journal of Materials Engineering and Performance 24 (2015) 3169-3179.
41. S.A. Hayes, P. Yu, T.J. O'Keefe, M.J. O’Keefe, J.O. Stoffer, The phase stability of cerium species in aqueous systems, Journal of the Electrochemical Society 149 (2002) C623.

42. B.R.W. Hinton, L. Wilson, The corrosion inhibition of zinc with cerous chloride, Corrosion Science 29 (1989) 967-985.

43. Y.-T. Cheng, C.-M. Cheng, Effects of "sinking in" and "piling up" on estimating the contact area under load in indentation, Philosophical Magazine Letters 78 (2010) 115-120.

44. A. Leyland, A. Matthews, On the significance of the H/E ratio in wear control: a nanocomposite coating approach to optimised tribological behaviour, Wear 246 (2000) 1-11.

Cite this article as: Kartsonakis IA, Koumoulos EP \& Charitidis CA: Advancement in corrosion resistance of AA 2024-T3 through sol-gel coatings including nanocontainers. Manufacturing Rev. 2017, 4, 2. 